\title{
La Economía Social exportadora de Sevilla: Un análisis exploratorio
}

\section{Macarena Pérez-Suárez y Arturo Gutiérrez Fernández}

\section{RESUMEN}

Andalucía ha mostrado en los últimos años su dinamismo exportador además de experimentar un incremento del peso de la Economía Social en su PIB.

Este artículo comprueba el aumento de las exportaciones andaluzas y demuestra que la internacionalización es una necesidad competitiva. Nos centraremos en cómo las empresas de Economía Social conforman un sector revelador en este sentido, destacando la provincia de Sevilla por sostener el mayor peso de empresas de la Economía Social andaluza y una parte distinguida del tejido exportador regional.

A causa del desconocimiento de la influencia de este sector en el crecimiento y la inexistencia de bases de datos relacionales que permitan conocer cómo opera la Economía Social andaluza, nuestro objetivo ha sido profundizar en la evolución de la actividad exportadora regional, desde una visión retrospectiva, y, más concretamente, en el desempeño exportador de la Economía Social sevillana.

PALABRAS CLAVE: Exportaciones, Economía social, Innovación, Nivel de Internacionalización.

CLAVES ECONLIT: F430, F230, M160, P130.

Cómo citar este artículo: PÉREZ-SUÁREZ, M. \& GUTIÉRREZ, A. (2015): "La Economía Social exportadora de Sevilla: Un análisis exploratorio", CIRIEC-España, Revista de Economía Pública, Social y Cooperativa, 84, 63-100.

Correspondencia: Macarena Pérez-Suárez, Profesora sustituta interina de la Universidad de Sevilla, miembro del Grupo de Investigación de Planificación y Análisis Económico de la Universidad de Sevilla, E-mail: mperez32@us.es; Arturo Gutiérrez Fernández, Catedrático de Economía Aplicada III de la Universidad de Sevilla, Director del Grupo de Investigación de Planificación y Análisis Económico. E-mail: arguti@us.es. 


\title{
L'économie sociale d'exportation de Séville : une analyse exploratoire
}

RÉSUMÉ : L'Andalousie a montré au cours des dernières années son dynamisme en matière d'exportations et a connu une hausse du poids de l'économie sociale dans son PIB.

Cet article analyse la hausse des exportations en Andalousie et montre que l'internationalisation est une nécessité compétitive. Nous étudierons la manière dont les entreprises de l'économie sociale constituent un secteur révélateur de cela, en mettant en avant la province de Séville qui soutient la majorité des entreprises de l'économie sociale andalouse et une partie distincte du réseau d'exportation régional.

En raison de la mauvaise connaissance de l'influence de ce secteur sur la croissance et de l'absence de bases de données relationnelles permettant de savoir comment fonctionne l'économie sociale andalouse, nous avons souhaité mieux connaître l'évolution des exportations régionales, avec une vision rétrospective, et, plus concrètement, les performances d'exportation de l'économie sociale sévillane.

MOTS CLÉ : Exportations, Économie sociale, Innovation, Niveau d'internationalisation.

\section{The exporting Social Economy of Seville: an exploratory analysis}

\begin{abstract}
In recent years, Andalusia has shown rising export growth. At the same time, the weight of the social economy in the region's GDP has increased.

This article verifies the increase in Andalusian exports and shows that internationalisation is a competitive necessity. It focuses on how social economy companies are a particularly revealing sector from this point of view, highlighting the province of Seville because it holds the greatest weight of Andalusian social economy enterprises and a considerable part of the Andalusian business network.

Because of the lack of knowledge of this growing sector's influence and the absence of relational data bases that reveal how the social economy of Andalusia operates, the goal of this research was to discover more about the evolution of regional export activity, from a retrospective point of view, and, specifically, the export performance of Seville's social economy.
\end{abstract}

KEY WORDS: Exports, social economy, innovation, level of internationalization. 


\section{1.- Introducción}

Las economías y las empresas deben ser competitivas en una economía global como la actual, pues se requiere que la demanda exterior adquiera un peso cada vez mayor, para lo que hay solo dos alternativas: producir de forma más eficiente que los demás o producir bienes y servicios diferenciados y de más calidad, es decir, con mayor valor añadido (Gutiérrez et al., 2014).

La crisis ha evidenciado, que la economía española y la andaluza necesitan crecer bajo las premisas de un nuevo modelo productivo sostenible. Asimismo, la mayoría de los expertos coinciden en la descripción del ADN de nuevas actividades económicas, fundamentado en una producción con alto valor añadido tanto en mano de obra de alta cualificación, como en innovación y uso intensivo de TIC.

La vigente Estrategia Europa 2020 (Comisión Europea, 2010), apuesta por alcanzar un crecimiento sostenible que se apoye en el conocimiento y la innovación, que contribuya a aumentar la competitividad de la economía. Es decir, un crecimiento basado en la internacionalización de las economías, y cuya vinculación es directa con la competitividad. Hoy ser más competitivos es una necesidad para las empresas y las economías, por eso no deja de ser una preocupación constante de los estudiosos de la economía conocer la competitividad de los territorios, su evolución y, a su vez, descubrir cuáles son los sectores más competitivos.

Llegados a este punto, consideramos oportuno limitar la competitividad, entendida como la capacidad de adaptación del producto y la calidad en la atención al cliente. Constituyendo la misma un elemento que impulsa considerablemente al proceso de internacionalización de las pymes. No alude tanto a la situación de los mercados en los que se opera habitualmente, como al estado de preparación para asumir nuevos retos, aprovechando los mismos como una ventaja competitiva frente al resto de competidores.

En un proceso como el apuntado, las empresas de Economía Social van a desempeñar sin duda un importante papel, pues la competitividad depende, cada vez más, del modo en que las empresas combinan recursos humanos, tecnología y organización empresarial (Gutiérrez Fernández et al, 2012:151). El nuevo paradigma dicta que los recursos que hoy permiten ser más competitivas a las economías tienen que ver con los activos intangibles ya citados: conocimiento y tecnología. De manera, que las industrias manufactureras de mayor contenido tecnológico son las más dinámicas y ven crecer más su comercio internacional (Gutiérrez et al., 2012:182). 
Concretamente, pues, en este trabajo analizaremos el comportamiento o desempeño exportador de las empresas de Economía Social. Incidiendo en el crecimiento de la economía andaluza, y en el que la Economía Social es un soporte indiscutible, pues ocupa un lugar destacado en la economía cíclica de la región como lo evidencian sucesivamente los informes estadísticos de la Economía Social Andaluza (CEPES-Andalucía). Documentos, que además recogen, que en las principales magnitudes de la economía andaluza tienen peso las cooperativas y las sociedades laborales como formas jurídicas principales, y donde estas empresas actúan como agentes capaces de aglutinar la función económica de crear riqueza con eficiencia y la función social de distribuirla con equidad (Millán y Navarro, 2008:228). Tanto es así, que en 2001 la Economía Social Andaluza representaba más del 12\% del PIB andaluz, según expone CEPES-Andalucía en su informe anual de 2001, y al finalizar 2013, el 13\% del PIB andaluz según fuentes de la administración pública regional (Pérez-Suárez y Espasandín, 2014:67). A lo que hay que añadir, que su comportamiento en los actuales tiempos de crisis, está dando una respuesta menos desfavorable que la economía tradicional capitalista en parámetros como, por ejemplo, la destrucción de empleo (González y García, 2012:43).

Como manifiesta González y García (2012), la Economía Social y el desarrollo territorial definen progresivamente un binomio con claras repercusiones bidireccionales, pues sustancialmente ante cambios sociales y una crisis como la actual proporcionan herramientas de actuación muy reveladoras derivadas de sus propias características y estructuras empresariales. En nuestro caso se ponen de manifiesto en factores decisivos, como es la internacionalización mediante la exportación e innovación empresarial.

Por su parte, la internacionalización ha sido definida por Welch y Luostarinen (1988) como un proceso de implicación creciente en operaciones internacionales. Siendo a su vez un proceso detallado por Johanson y Wiedersheim Paul (1975), al afirmar que una empresa pasa por cuatro etapas en la penetración en un mercado exterior. En las primeras etapas destacan las exportaciones no regulares sin implicación de recursos para continuar con la iniciación de la cadena de establecimiento en el exterior que se realiza a través de representantes independientes con un compromiso mayor de recursos, para finalmente, avanzar con exportaciones regulares.

Para Tabares (2012:68), la teoría por procesos de Uppsala y la cadena de establecimiento sigue siendo la teoría de internacionalización más empleada por las pequeñas empresas, tal como trata en su revisión analítica de los principales planteamientos en la internacionalización de pequeñas y medianas empresas de Europa y Colombia. Dentro de este enfoque conocido como "internacionalización desde la perspectiva de procesos", las empresas se internacionalizan a través de una serie de etapas de crecimiento ordenado y se incrementan de acuerdo con su desarrollo. Bien es cierto que, la teoría de la internacionalización de Uppsala define la internacionalización de la empresa como un proceso gradual de decisiones acumulativas basado en las interacciones permanentes entre el desarrollo del conocimiento sobre mercados exteriores y el compromiso de recursos en dichos mercados. Tanto es así, que la decisión de selección de mercados exteriores establece a qué países debe dirigirse la empresa en función de la distancia psicológica percibida. 
Especialmente, Martín-Armario, Rastrollo-Horrillo y González-Robles (2009) se interesaron por estudiar la internacionalización de las empresas en España a partir del conocimiento experimental como elemento determinante de los resultados en mercados externos. Dichos autores identificaron la forma de hallar la relación que permitiera comprender el conocimiento experimental de las empresas como un procedimiento en el cual las organizaciones inician el proceso con una aprehensión del conocimiento individual hasta lograr un conocimiento organizacional con el tiempo, a través de un proceso de socialización, externalización e internalización. Es por lo que Tabares (2012:76) lo tiene claro, la teoría por procesos sigue siendo la teoría de internacionalización más empleada de las pymes por el grado de certeza que se genera en torno al stock de conocimiento en los mercados externos, y ha planteado, que cuando las empresas comienzan a depender en un porcentaje superior al $25 \%$ de las ventas en mercados internacionales, aumentan sus posibilidades de buscar mercados diferentes.

En 2007, la Federación de Cooperativas de Trabajo Asociado (Faecta) realizó un estudio de la internacionalización de los mercados. Un diagnóstico de la situación de las cooperativas, en el que se afirma que Andalucía representa dentro del total exportador el 7,3\%, siendo lo más significativo el incremento del $23,5 \%$ respecto del año 2006. Y señalando como principales mercados de exportación de Economía Social: Francia, Reino Unido y Portugal, además de los mercados de exportación en otras áreas de desarrollo económico, como Marruecos o Polonia.

Secuencialmente, en el caso del cooperativismo español ha comenzado hace algunos años a ser importante el volumen de producto con marca propia y el volumen de las exportaciones. Así lo demostraban García et al. (2011), "la Confederación de Cooperativas Agrarias de España indica que en 2009 el $35 \%$ de las cooperativas españolas vendían en otros países de la Unión Europea e incluso el $15 \%$ exporta a otros países no comunitarios...aunque la implantación exterior de las cooperativas españolas es escasa, solo el 7,41\% de las cooperativas de segundo grado se estable en el exterior y apenas la mitad de las cooperativas de primer grado. Al respecto, hay quien afirma que la agroindustria alimentaria española suele presentar un escaso interés por la internacionalización derivado de problemas de dimensión y formación empresarial. Es por ello, que las cooperativas agrarias por destinos exportan a mercados comunitarios: Alemania, Francia, Portugal, Holanda y Reino Unido", como ya se señalaba anteriormente que sucede en Andalucía. Además, en los últimos años se aprecia en el sector de Economía Social cierta proactividad con movimientos horizontales y verticales de fusiones de cooperativas de primer grado y de integraciones en cooperativas de segundo grado y de alianzas entre grupos de cooperativas de variados productos (podemos citar los ejemplos de Hojiblanca, Agrosevilla, Oviporc, etc.) que pretenden incidir en la línea de abaratar costes y adquirir la dimensión suficiente para acceder a mercados exteriores.

Aunque el modelo al que nos referimos de empresa es vital para estimular el desarrollo local (Pérez y Carrillo, 2000) y regional, la Economía Social no está eximida de competir en el mercado global si se desea garantizar su sostenibilidad económica y social. Puesto que la internacionalización de las empresas y de las economías es una necesidad competitiva de primer orden, especialmente, en 
momentos en que muchos mercados locales no consiguen absorber la oferta generada por el sistema empresarial. Siendo ello, sin duda, una decisión de carácter estratégico.

Ahondando en esta última premisa y en lo que acontece en Andalucía, Borrell y Relaño (2009) han comprobado, como las empresas andaluzas utilizan más de una vía de internacionalización, y específicamente, que las empresas innovadoras se están introduciendo en el proceso de internacionalización mediante diversas formas (exportación directa, exportación indirecta a través de distribuidoras comerciales, inversión directa, proyectos de l+D, etc.), algo que verificaran otras investigaciones desde entonces.

Pérez-Suárez y Espasandín (2014:75) profundizan en ello a partir de Moral y Lanzas (2008), cuando nos dicen que la internacionalización favorece la innovación, la especialización y el aprovechamiento de economías de escala. A medida que la empresa puede ampliar su mercado objetivo, el comportamiento estratégico de ésta varía. En opinión de Alonso y Álvarez (2003), pues, la proyección internacional parte de la producción empresarial convertida no solo en una componente obligado para la ampliación y mejora de la posición competitiva en el exterior, sino también en un resorte para la defensa de la que mantienen en el mercado local. Unido ello, a los autores que entienden la actividad exportadora como un proceso innovador, capaz de generar e incorporar conocimientos para dar respuestas creativas a los problemas del momento.

En síntesis y a la luz de los datos previamente presentados, son dos los motivos principales que justifican esta investigación: aumentar los conocimientos en cuanto a la evolución de la actividad exportadora y su influencia en el crecimiento de la economía andaluza y sevillana; y comprender el papel que viene desempeñando la Economía Social a partir de una serie de variables que inciden en la internacionalización y la competitividad.

Hemos partido, pues, de definir un problema detectado: El desconocimiento del papel que desempeñan las empresas exportadoras andaluzas y sevillanas, y de forma especial las sevillanas de Economía Social como motores de la exportación en el crecimiento de la economía y la importancia de algunos factores internos que lo motivan. Sin obviar, en ello, la falta de fuentes de información directas actualizadas de Economía Social, así como, las escasas investigaciones nacionales y regionales a pesar de ser un tema trascendente y novedoso.

Para resolver dicho problema nos hemos fijado un objetivo general: Conocer como está evolucionando el sector exportador andaluz y sevillano y de forma especial las empresas de Economía Social (cooperativas y sociedades laborales) en cuanto a su desempeño exportador y la importancia de algunos factores que motivan la internacionalización: sector, tamaño, resultados de la innovación, resultados económicos, nivel de internacionalización y comercio electrónico.

En esta investigación, se realiza una aproximación a la respuesta que la economía exportadora, y en especial la Economía Social, ofrece al crecimiento de Andalucía, aunque tomamos como refe- 
rencia la Economía Social hispalense basándonos en una muestra de empresas para detectar su comportamiento.

El objetivo general lo hemos dividido en seis objetivos específicos, que una vez logrados, nos permita afirmar que hemos alcanzado el general. Dichos objetivos son los siguientes:

- Conocer la evolución de los sectores de exportación andaluz y sevillano, y especialmente, de las empresas de Economía Social.

- Saber si el sector económico en el que están presentes las empresas sevillanas de Economía Social influye en su orientación exportadora.

- Conocer la relación que hay entre el tamaño de las empresas sevillanas de Economía Social y su desempeño exportador.

- Revelar si hay relación entre las innovaciones y el desempeño exportador de las empresas sevillanas de Economía Social.

- Saber si crece la facturación de exportaciones con respecto al total en el tiempo, así como, con el uso de internet como canal de ventas o distribución.

- Hacer constar si hay una relación entre la presencia en más mercados internacionales por parte de las empresas de Economía Social sevillanas y el desempeño exportador.

Para alcanzar los objetivos definidos planteamos una investigación descriptiva, explicativa, longitudinal y exploratoria, que se estructura en los cinco apartados siguientes: en primer lugar, se desarrolla el marco teórico, se plantean y justifican las hipótesis y se diseña el modelo conceptual; en segundo lugar, se describen los métodos de captación y análisis de datos; en tercer lugar, presentamos los resultados para finalmente detallar y discutir las conclusiones, acompañadas de las limitaciones y las líneas futuras de investigación.

\section{2.- Revisión de la literatura y diseño del modelo conceptual}

La investigación tiene como punto de partida, el reconocimiento de la relación real que hay entre el entorno y la internacionalización de las empresas, debiendo llegar a comprender el papel que desempeña hoy la competitividad como objetivo intermedio de crecimiento de las economías.

A su vez, esta investigación es exploratoria, pues adelanta una investigación en curso y es longitudinal a los trabajos realizado por el grupo de investigación (Planificación y Análisis Económico de la Universidad de Sevilla), con objeto de comprobar hacia dónde se dirige el modelo productivo andaluz y tratar de detectar la competitividad de la economía andaluza y de sus provincias a partir del desempeño exportador (Gutiérrez et al., 2012). 
En base a lo citado, recalcamos que para nosotros tiene un significado excepcional la Economía Social como sector generador de empleo, renta y riqueza de características propias. De la misma manera, partimos de un paradigma en el que se basa la economía industrial, la relación entre estructura de los mercados-conducta de las empresas y resultados.

Cuando David Ricardo enunció la teoría de la ventaja comparativa, estaba mostrando las ventajas que presentaba el comercio para los países o regiones si se especializaban en las actividades con mayor productividad. Actualmente, unos países desbancan a otros de las posiciones que ocupan estos en el mercado mundial, algo que no puede explicarse solamente de acuerdo a los principios teóricos convencionales basados en la teoría de la ventaja comparativa, a la vez que somos conscientes que no hay una teoría generalmente aceptada (Porter, 1991:25).

La principal causa que ha llevado a equívocos acerca del término competitividad, tiene su origen en el empeño de mantener teorías y modos de pensar que tienen escasa capacidad explicativa del mundo real, es decir, es ilusorio mantener que los mercados funcionan bajo las reglas de la competencia perfecta, que los rendimientos son decrecientes o constantes, o que es necesario partir de las ventajas comparativas intersectoriales, en lugar de las ventajas absolutas intrasectoriales. Para David Ricardo, la ventaja comparativa intersectorial era algo distinto de la ventaja intrasectorial que se asocia a la ventaja absoluta. Y la confusión viene de contemplar, bajo el nombre de ventaja comparativa, elementos diferentes y contradictorios que proceden de las teorías originales de Ricardo y Smith tal como señala Guerrero (1995:107).

La internacionalización de las empresas se ha convertido en un fenómeno que ha llamado la atención de muchos académicos e investigadores (Martín-Armario, Rastrollo-Horrillo y González-Robles, 2009). A partir de la asimilación por parte de las empresas de la internacionalización a sus procesos como una estrategia de incursión en mercados extranjeros, convirtiéndose la internacionalización en materia de estudio indispensable para el área de los negocios internacionales (Tabares, 2012:70).

En la revisión de la literatura acerca de la internacionalización se hallan tres grandes grupos de estudios: Ios teóricos y de encuadre metodológico sobre la internacionalización empresarial; aquellos que se han realizado sobre aplicaciones prácticas de la internacionalización empresarial en los países asiáticos, y los estudios empíricos vinculados a la internacionalización en el resto del mundo como tercer bloque. Destacando los dos últimos por su cercanía a la ciencia económica.

La presente investigación puede fundamentarse en tres enfoques teóricos: el enfoque económico, el secuencial y el estratégico, cada uno con sus teorías acerca de la internacionalización de la empresa. Tabares, Anzo y Estrada (2014:316) dividen en dos perspectivas de estudio los citados enfoques: la perspectiva económica y la perspectiva de procesos (Johanson y Wiedersheim-Paul, 1975). Abordando la internacionalización a partir del enfoque por procesos explicada a través de los Modelos relacionados con la Innovación (innovation-related models) y el Modelo Uppsala (U-model). De acuerdo con los autores del modelo U-model, Johanson y Wiedersheim-Paul (1975), las empresas inician su pro- 
ceso de internacionalización con la comercialización de sus productos en el mercado local y luego empiezan a internacionalizarse a través de una serie de decisiones incrementales destinadas a conocer y experimentar el mercado internacional. Cabe destacar que, en 2009, se presentó el Modelo Uppsala revisado, y que esa revisión ha partido del reconocimiento de oportunidades (Tabares, Anzo y Estrada, 2014).

Para autores como García, Cañizares y Roldán (2011), la internacionalización es una de las fuerzas más importantes y generalizadas que ha cambiado el entorno competitivo de los negocios, pues ha permitido abrir los mercados nacionales a nuevos competidores, a la vez que ha creado nuevas oportunidades de negocio, tanto para pequeñas como grandes empresas. Buscar nuevos mercados y tomar la decisión de internacionalización son estrategias de crecimiento y aprovechamiento de recursos y capacidades, y la selección del modo de entrada en los mercados exteriores es una decisión clave en esa estrategia empresarial (Calderón et al., 2007).

El aumento de la presencia exportadora española puede ser constatado en los ámbitos macro y microeconómico, aunque en el caso de la economía española su cuota de mercado se mantiene hace décadas entre el 1,7 y 2,0\% (Nadal, 2005). En el ámbito macroeconómico son numerosos los estudios realizados, si bien recientemente Gutiérrez et al. (2014), ha comprobado las bases en las que se ha asentado el comportamiento exportador en la internacionalización de la economía española y andaluza en el período 1999-2009 (Gutiérrez et al., 2012:208). Otros autores como García et al. (2012), han utilizado una muestra de empresas exportadoras españolas para el periodo 2001-2010, para confirmar entre otros rasgos, que las empresas exportadoras son de mayor tamaño, más eficientes, realizan más operaciones de inversión directa y suelen estar en mejor posición financiera que aquellas empresas que no exportan. La internacionalización les permite disminuir la dependencia de los mercados locales, que tan negativas repercusiones tiene en los momentos de recesión, algo que también argumenta Herrero (2003:104).

El incremento de las ventas para las empresas es un sinónimo de crecimiento, de ahí, el impacto económico para estas que genera el fortalecimiento de su internacionalización. Al respecto, Escandon y Hurtado (2014) estudian los factores internos de la empresa en relación directa al desarrollo exportador, pues los factores internos de una organización pueden determinar su capacidad de internacionalizarse. En nuestro caso, podemos identificar entre los factores internos de las empresas de Economía Social, con carácter general, las variables consideradas en esta investigación.

Pasemos, pues, a plantear las hipótesis de investigación y diseñar gráficamente el modelo conceptual.

\section{H1: A mayor exportación regional, mayor crecimiento de la economía.}

Hemos creído oportuno contextualizar el marco macroeconómico de Andalucía en 2002 y 2013, para posteriormente referirnos a nuestros resultados alcanzados. 
Considerando oportuno, pues, destacar que el año 2002 andaluz cerró con un crecimiento real del PIB del $3 \%$, superando el esperado para la economía española (2,9\%, según el INE, 2014). Bien es cierto que a lo largo de estos años las tasas reales de variación anual (\%) pasaron de positivas a negativas tanto en España como en Andalucía. Si cabe diferenciar el dinamismo relativo de Andalucía en términos de actividad productiva, pese a una balanza comercial deficitaria.

Tanto es así que en 2013, el PIB siguió presentando un descenso superior al 1\%,(-1,2\% variación de volumen-tasa de variación interanual, 2013/A) (INE, 2014) aunque el sector exterior aportó 0,7 puntos al crecimiento del PIB (Pérez-Suárez y Espasandín, 2014:67). En este contexto, el balance del año 2013 en Andalucía fue de una caída real del PIB del 1,3\%, prácticamente igual que la media nacional $(-1,2 \%)$, y casi un punto inferior a la del año precedente (-2\%) (Secretaría General de Economía de Andalucía, 2014). Aún así, el descenso del PIB fue inferior al experimentado en años previos, lo que podría estar reflejando que la economía española está registrando un punto de inflexión hacia una senda de mejora (Álvarez, Vázquez y Figueroa, 2013).

\section{Tabla 1. Marco Macroeconómico de Andalucía 2002 y 2013}

\begin{tabular}{|l|cc|cc|}
\hline & \multicolumn{5}{|c|}{ MARCO MACROECONÓMICO } \\
\hline & ESPAÑA & ANDALUCÍA & ESPAÑA & ANDALUCÍA \\
\hline PIB & $2,9 \%$ & $3 \%$ & $-1,2 \%$ & $-1,3 \%$ \\
\hline Balanza Comercial & Saldo negativo & Saldo negativo & Saldo negativo & Saldo negativo \\
& Tasa de cobertura & Tasa de cobertura & Tasa de cobertura & Tasa de cobertura \\
& $76 \%$ & $94 \%$ & $93,9 \%$ & $86,7 \%$ \\
& & & & \\
& & & &
\end{tabular}

FUENTE: Elaboración Propia a partir de los Informes de Coyuntura Económica de la Junta de Andalucía de 2002 y 2013. Consejería de Economía, Innovación, Ciencia y Empleo a partir del IECA e INE. Utilizamos además de los Informes de Comercio Exterior del Ministerio de Economía y Competitividad para detallar la tasa de cobertura.

Por su parte, Andalucía a lo largo de 2014 ha afianzado la trayectoria de recuperación iniciada en la segunda mitad del año anterior, con un dinamismo superior respecto al conjunto de la economía española. No obstante, este mejor comportamiento está siendo de menor intensidad del otorgado por las previsiones del FMl y la OCDE. Conforme a ello, la administración regional en el segundo semestre de 2014 estimaba un incremento real del PIB del 1,4\% en 2014, previsión de crecimiento económico que contrasta con el descenso observado en $2013(-1,3 \%)$ (Secretaría General de Economía de Andalucía, 2014). Lo que es traducido desde el punto de vista de la oferta, en un crecimiento de todos los sectores productivos. Y desde el lado de la demanda, en que la demanda regional pasaría a ser positiva en 2014, apoyada en el crecimiento del consumo y de la inversión (Fundación Unicaja, 2014). 
El impacto macroeconómico de la actividad exportadora, especialmente, como promotor del crecimiento económico de un país ha sido corroborado empíricamente por numerosos trabajos. Recientemente, Esteve, Pallardó y Requena (2009) recogen la relación entre actividad exportadora y los resultados empresariales confirmando que las pequeñas empresas que deciden exportar gozan de un mayor crecimiento, y la probabilidad de que fracasen como negocio es significativamente menor a la de las compañías que no exportan.

\section{H2: Los sectores económicos exportadores tienden a influir de forma directamente pro- porcional en el desempeño exportador de las empresas sevillanas de Economía Social.}

Abundante es la experiencia empírica y teórica de las últimas décadas sobre las oportunidades de expansión y crecimiento económico que brinda el comercio, pues proporciona importantes beneficios a los países que participan en él, permitiendo que determinados países y/o áreas económicas alcancen mayores cotas de bienestar.

El sector exterior desde finales de 2009 se ha convertido en motor de la economía andaluza y de la española, pero al estar poco internacionalizadas ambas economías la contribución al crecimiento ha tenido una baja significación para ambas (Gutiérrez et al., 2014).

El sector al cual pertenece una empresa no solamente ejerce una influencia sobre la toma de decisiones estratégicas, sino que también afecta la rapidez con que las pequeñas empresas se internacionalizan (Oviatt y McDougall, 2005). También es innegable que existen sectores más exportadores, por lo tanto la capacidad de internacionalización de algunas empresas se presenta según el tipo de sector. Bien es cierto, además, que la dinámica del sector de actividad económica de una empresa puede depender de la tradición exportadora del sector. En consecuencia, diversos son los autores que abordan la gran rivalidad sectorial asociada positivamente con la actividad exportadora de una organización.

Wernerfelt (1984) afirma, que si las características del sector económico al que pertenece la empresa tienen una relación positiva con la internacionalización temprana de las pymes, la perspectiva de los recursos y capacidades permite guiar la formulación de las estrategias de las firmas diversificadas. Posteriormente, se llega a plantear que la relación positiva reside en el conjunto de recursos, prestando atención a los recursos internos de la empresa y en la forma como estos son adquiridos 0 desarrollados, determinando que éstos últimos marcan la posición de la empresa para enfrentar el mercado global.

Otras investigaciones han mostrado que, en las fases más tempranas, la internacionalización de las empresas puede estar influida por las características del sector, en concreto, por la fase del ciclo de vida en la que se encuentre. De lo que no hay duda, según se cita a Martín-Armario (2003), es de que: "la internacionalización permite que las empresas exploten mejor las economías de escala que pueden surgir de sus respectivos activos estratégicos en los sectores en que son más competitivas". 


\section{H3: A mayor tamaño de las empresas sevillanas de Economía Social, mayor debe ser su desempeño exportador.}

La Escuela de Uppsala (1975-1977) y las teorías sobre la innovación empresarial, proponen un enfoque gradual de la internacionalización iniciada a partir de determinado tamaño empresarial y consideran que la misma es tanto un proceso de aprendizaje sobre los mercados exteriores y compromiso incremental de recursos, como un producto de la innovación de la empresa. Estos enfoques secuencialitas suponen que el proceso de internacionalización se puede observar a través del cumplimiento de varias etapas lo que evidencia la evolución de los niveles de riesgo, control, experiencia y compromiso respecto a los mercados extranjeros.

Es por ello, que hay autores que evalúan una serie de variables relacionadas con el rendimiento en los mercados exteriores y sus medidas. En particular, dentro de los factores organizacionales podemos hablar de la confirmación empírica de que ciertas características organizacionales están relacionadas con la obtención de un rendimiento exportador superior, como es el caso del tamaño de la empresa (medido en términos de números de empleados, cifra de negocios o activo total) (MartínArmario, 2003).

García et al. (2007), por su parte, defiende que el tamaño empresarial es el paso previo de las empresas para tener éxito en su aventura exportadora, variable muy ampliamente estudiada y contrastada en la literatura por estudios como el de Fayos et al. (2011). Estos últimos, concluyen que el tamaño de la empresa, aunque no es un factor totalmente determinante del proceso de internacionalización sí parece que condiciona el proceso, tanto en la medida en que la internacionalización exige una estructura mínima, ya que las microempresas parecen menos propensas a internacionalizarse que las empresas de mayor tamaño.

Por su parte, Fernández y Nieto (2002) destacan además, que el tamaño de la organización medido a través del volumen de ventas y del número de trabajadores está relacionado con el compromiso internacional de la empresa, afirmando que las empresas más grandes son de hecho las más internacionalizadas.

Ciñéndonos a las empresas de Economía Social, tal como recogen Fayos, Calderón y Mir (2011:45), la vinculación con los mercados exteriores de las cooperativas se realiza prioritariamente a través de la exportación, debido ello, en demasiadas ocasiones, a su falta de dimensión.

Bajo dicha premisa, varios estudiosos coinciden en que uno de los retos más importantes de las cooperativas es la dimensión. Sin embargo, la dimensión no es un fin sino un medio. Un medio, para internacionalizarse, pero también para ganar competitividad, acceder a los canales de distribución y conseguir recursos para incrementar valor; aspectos todos que incidirán en el proceso de internacionalización (Fayos et al., 2011:48). 
Acercándonos más a nuestra materia de estudio, hay autores que demuestran que la calidad de la gestión mejora en relación directa al tamaño de las empresas, tanto en las cooperativas y sociedades laborales como en las entidades que no son de Economía Social, si bien en estas últimas la mejora se acentúa más. De lo que se deduce, que, o las empresas de Economía Social crecen o será muy difícil su supervivencia en un mercado altamente competitivo.

\section{H4: Las innovaciones son determinantes para un mayor desempeño exportador de las empresas sevillanas de Economía Social.}

Si asumimos, que la revolución tecnológica vigente tiene dos rasgos muy importantes: la velocidad con la que se producen los cambios y el carácter horizontal de las innovaciones, podremos fácilmente deducir, que dichos rasgos requieren del aparato productivo varios tipos de cambios (Gutiérrez et al., 2012:74).

El futuro de nuestros sectores productivos depende en gran medida de la innovación, y solo si tenemos empresas innovadoras, estas serán líderes, y con sus flujos comerciales y la influencia productiva que generan irán modificando el modelo productivo. Al respecto, se vincula la actividad innovadora de las empresas con su internacionalización, demostrando que las empresas exportadoras suelen caracterizarse por su mayor nivel de innovación. Y más específicamente, Wong y Singh (2004) señalan que la innovación tecnológica hace más probable que las empresas incursionen en el mercado internacional, demostrando la existencia de una relación positiva entre innovación y desarrollo exportador.

Para el caso de las pymes, la adopción de tecnologías es aún más determinante dentro de su proceso de internacionalización porque les permite superar ciertas limitaciones y acentuar su ventaja competitiva. Una empresa se vuelve innovadora conforme sus factores internos se lo permitan (ingresos, nivel de ventas, recursos humanos), y siempre bajo la influencia del entorno, es decir, según el nivel tecnológico característico del entorno al cual pertenece, que incentiva y obliga a la empresa a igualar dicho nivel para garantizar su permanencia en el mercado. Es una de las razones aparte, por las que las empresas jóvenes con actividad exterior necesitan apoyarse en su capacidad de innovación.

La innovación tiene efectos positivos sobre el crecimiento económico a largo plazo de cualquier país o región, y en nuestra economía es esencial para avanzar hacia un nuevo modelo productivo sostenible (Gutiérrez et al., 2012:38). La capacidad de innovación tecnológica de un país se apoya fundamentalmente en su esfuerzo de inversión en investigación y desarrollo tecnológico (l+D), así como, en el esfuerzo para conseguir un capital humano capacitado para adquirir conocimientos y desarrollar tecnologías, y en la existencia de un tejido empresarial que sea capaz de aprovechar las fuentes de conocimiento y tecnología a su alcance para producir productos y servicios novedosos que generen negocio y mejoren su competitividad (COTEC, 2010:24). La innovación puede ser tal como hemos indicado, de producto y de proceso, pero su origen puede proceder de la investigación y desarrollo $(I+D)$, de la difusión de conocimiento en los mercados mediante la incorporación o imitación, 0 simplemente de la experiencia (Zozaya, 2005:8). 
En Andalucía, generalmente, las empresas más pequeñas (precisamente las que predominan en la Economía Social), tienen mayores dificultades y retraso en materia de innovación (Espasandín et al., 2003:151). Trabajos como los de Fernández (2004), Coronado y Acosta (2002), García, Palma y Pomares (2002), Aguado, Pomares y Palma (2000), entre otros, lo confirman.

En los últimos años se ha incrementado la presencia de cooperativas y sociedades laborales en los mercados internacionales, lo que ha posibilitado un mayor uso de las nuevas tecnologías, una mayor especialización de las variedades cultivadas y de las innovadoras técnicas comerciales empleadas (Pérez-Suárez y Espasandín, 2014:69). Es la confirmación empírica de que ciertas características organizacionales están relacionadas con la obtención de un rendimiento exportador superior, como son los recursos disponibles, habiendo comprobado, que las empresas de gran tamaño y aquellas con adecuados recursos humanos e innovación, obtienen mejores resultados en los mercados exteriores.

\section{H5: Cuantos más años lleven las empresas de Economía Social internacionalizadas, mayo- res serán sus ventas en el exterior y más usarán internet como canal de ventas o distribución.}

Según Weiss, López, y Medina (2011), el análisis de la literatura sobre el desempeño exportador de una empresa pone de manifiesto que no existe un consenso de cuales debieran ser las medidas del mismo, lo que ha generado estudios empíricos con diferentes indicadores, haciendo, ello, muy difícil la comparación.

Para varios autores, las medidas de desempeño exportador relevantes dependerán de distintos factores, tales como el marco de referencia, la perspectiva de los stakeholders, o la unidad de análisis, entre otros. Cuyas medidas de desempeño exportador depositan su peso principal en las medidas económicas definidas a partir de las ventas y utilidades provenientes de la exportación. Lo que se puede complementar, afirmando que el desempeño exportador es el resultado compuesto de las ventas internacionales de una empresa, la cual incluye tres sub-dimensiones: ventas, rentabilidad y crecimiento de las exportaciones (Morgan y Katsikeas, 1998).

Más recientemente, Martín-Armario (2003) asiste a esta importancia de las ventas como indicador clave del rendimiento exportador. La más común es la propensión exportadora que, sin embargo, ha sido criticada por no reflejar la dimensión competitiva del éxito exportador. Otra medida ampliamente empleada y con éxito como indicador es el crecimiento de las exportaciones, pero hay que tener precaución en su uso, pues se puede exagerar el rendimiento a causa de una escalada de precios y/o de un mercado en crecimiento, o disminuirlo a causa del efecto de la curva de la experiencia y el deterioro de la demanda.

A pesar de la creencia de que distintos factores empresariales condicionan la estrategia de expansión internacional y ejercen una notable influencia en el resultado exportador (ventas en el exterior) de la empresa (Bobillo et al., 2010), se ha constatado tanto la dificultad de definir relaciones causales como la ausencia de consenso sobre qué aspectos del perfil empresarial ejercen mayor influencia 
en los resultados exportadores de la empresa. Sin embargo, pensamos que un mayor desempeño exportador de la empresa condiciona un aumento del volumen de ventas en el exterior.

Simultáneamente, el desarrollo de las TIC (circulación de a información en tiempo real), se puede considerar como la principal causa de la globalización de la economía, que, con la localización es la otra fuerza impulsora actualmente para fomentar el desarrollo regional. Y aunque las soluciones globales deban ser tenidas en cuenta, las necesidades locales y los condicionantes propios nos deben permitir definir el futuro. Bien cierto es, que el vínculo entre la inversión en TIC y el crecimiento ha sido investigado por una gran cantidad de investigaciones a nivel de "empresa" como Lehr y Lichtenberg, Brynjolfsson e Hitt (Gutiérrez et al., 2012:100-101).

Según Chamorro y Miranda (2003:1), el potencial de Internet como canal de distribución ha sido resaltado en innumerables estudios. Así, casi todos los trabajos coinciden en señalar como principales ventajas las siguientes: el incremento de la base de clientes a nivel internacional, acceso directo al mercado de consumidores finales y el ahorro de costes.

En nuestro país, a pesar del imponente retraso en la implantación del comercio electrónico con respecto al resto de países desarrollados, todavía existe una importante oportunidad para las empresas que apuesten por este canal de ventas, si desarrollan un plan de implantación coherente y acorde con las características internas y a las propias de su entorno competitivo. Según Meseguer, RodríguezArdura, y Vilaseca, (2003:21), el promedio de volumen de negocio generado por el consumidor español experimentó un cambio de tendencia en el año 2000, siendo ascendente desde entonces.

Para Yusta, Ruiz y Zarco (2010:175), en la aplicación de Modelo Tam de Davis et al. (1989), las innumerables ventajas que ofrece internet están favoreciendo que multitud de empresas decidan ofrecer también sus productos o servicios al consumidor final a través de este canal, asociando para ello las ventajas del comercio electrónico (por ejemplo, disponibilidad continua o eliminación de barreras geográficas) a su oferta comercial.

Dando paso a la siguiente hipótesis, Moreno, Peña y Hernández (2008) concluyen que el volumen de ventas exteriores se relaciona de una manera positiva con la estrategia de liderazgo en costes y con la diversificación de mercados. Conjuntamente, el nivel de internacionalización considerado como el número de mercados extranjeros en los que opera la empresa, se relaciona de forma positiva con el volumen de exportaciones.

\section{H6: A mayor desempeño exportador de las empresas sevillanas de economía social, mayor será su nivel de internacionalización.}

Llegados a la hipótesis presente, es más que necesario delimitar que entendemos en esta investigación por desempeño exportador -export performance- desde la definición de Madsen (1987), entendiendo por el mismo el resultado de una constante interacción de la organización con otros grupos 
de variables, a saber, su propia estructura organizativa, su rendimiento, medio ambiente y sus propias estrategias. Es decir, el resultado obtenido por la empresa en los mercados de exportación como consecuencia de la interacción de factores externos e internas de la empresa (Losada et al., 2006).

Hill et al. (1990) recogen que la elección del modo de entrada al exterior se plantea en función de cómo difiere el compromiso de recursos, el nivel de control inherente a cada modo de entrada y el riesgo de que las ventajas específicas de la empresa (sus conocimientos) se diseminen en el exterior. De acuerdo con el enfoque secuencial del proceso de internacionalización de Uppsala (Johanson y Wiedersheim-Paul, 1975), la compañía comenzará exportando en aquellos mercados más cercanos y la expansión geográfica internacional se orientará hacia países más alejados a media que va ganando experiencia en los destinos previos.

Acercándonos a España, Esteve, Pallardó y Requena (2009:60) fijan una serie de regularidades en el comportamiento exportador de las empresas españolas en el período 1997-2005 en relación a la cartera de destinos de exportación. Llegando a proporcionar una descripción detallada sobre la evolución del patrón de exportación de las empresas. Siendo cierto que, la mayor parte de empresas comienzan exportando a un solo mercado y progresivamente van añadiendo mercados.

Respondiendo con cierta precisión a la justificación de esta variable en nuestro estudio, según Martín-Armario (2003) hay medidas no económicas, relacionadas con el mercado que son las utilizadas más frecuentemente para valorar el rendimiento exportador como son: el número de mercados en los que se opera, la penetración en el mercado de exportación, el acceso a nuevos mercados, la contribución de la exportación al desarrollo del mercado, etc. Lo cierto es, en definitiva, que la selección de mercados internacionales se convierte siempre en una decisión fundamental.

La síntesis de las hipótesis planteadas se concreta en el siguiente modelo conceptual.

\section{llustración 1. Modelo Conceptual de la Investigación}

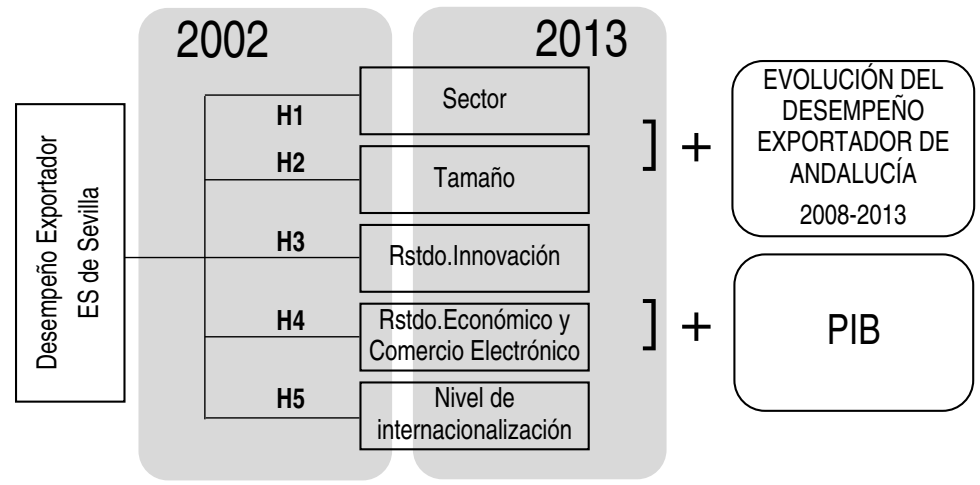

FUENTE: Elaboración Propia. 


\section{3.- Metodología}

Este apartado versa sobre el método de captación y tratamiento de datos y, en particular, contempla el detalle de las seis variables empleadas, la descripción de la población y la muestra, así como la enumeración de los métodos estadísticos empleados. Además de recoger nuestra aportación teórica a partir de la exposición de las variables determinadas, su denominación y comprensión en base a su verificación propia en la literatura, es decir, la selección de las variables de control es conforme a estudios previos de otros autores. Como así atesora la Tabla 2 en el despliegue del tipo de variables empleadas.

Seguidamente vamos a dividir el presente apartado en dos partes en cuanto al tratamiento de información. Es decir, nuestros resultados son producto en una primera parte, del tratamiento de fuentes secundarias (estadísticas oficiales suministradas por organismos oficiales como CEPES-Andalucía, el Instituto Nacional de Estadística, Extenda o la Consejería de Economía, Innovación, Ciencia y Empleo, etc.), en especial, la base de datos publicada por el Observatorio del Comercio Exterior de Andalucía de Extenda sobre empresas exportadoras de 2013 que ofrece una visión de la situación actual del tejido empresarial exportador andaluz, tanto por el número de empresas exportadoras como por su volumen de exportación. Mientras que en segunda instancia, hemos acudido al tratamiento de una fuente primaria acopiando una serie de datos seleccionados del tejido empresarial protagonista con el objeto de abordar un punto de vista retrospectivo.

En consonancia, para medir las variables seleccionadas, se diseñó un cuestionario semiestructurado con 34 preguntas, previamente testado entre colectivos de representantes de la Economía Social andaluza (CEPES-Andalucía) e investigadores experimentados en el sector económico objeto de la Universidad de Sevilla (equipos de trabajos de los grupos de investigación SEJ301:PYMES, gestión y competitividad y SEJ230:Planificación y Análisis Económico). Para posteriormente, recopilar los datos necesarios de una muestra representativa del sector de Sevilla como queda estipulado en la ficha técnica. 


\section{Tabla 2. Variables e Indicadores de la investigación}

\begin{tabular}{|c|c|c|c|c|}
\hline $\begin{array}{l}\text { Nombre de } \\
\text { la variable }\end{array}$ & $\begin{array}{c}\text { Concepto de la } \\
\text { variable }\end{array}$ & $\begin{array}{l}\text { Denominación } \\
\text { del Indicador }\end{array}$ & Tipo de variable & Autores \\
\hline $\begin{array}{l}\text { Orientación } \\
\text { Internacional }\end{array}$ & $\begin{array}{l}\text { Venta directa de una } \\
\text { empresa desde un } \\
\text { país a otro }\end{array}$ & Exportación & $\begin{array}{l}\text { Variable Dicotómica } \\
\text { Valor Si/No }\end{array}$ & $\begin{array}{l}\text { Escandón y Hurtado (2014); Tabares, Anzo, y } \\
\text { Estrada (2014); Arnoldo (2009); Moral y Lanzas } \\
\text { (2008); Egea y Guerrero (2007); De Velasco (2005, } \\
\text { 2009); Morello (2001); Aulakh, Kotabe y Teengen } \\
\text { (2000); Leonidou (1995); Barltlett y Ghosahll (1989). }\end{array}$ \\
\hline Tamaño & $\begin{array}{l}\text { Dimensión de la } \\
\text { empresa, quiere } \\
\text { expresar su estruc- } \\
\text { tura y/o volumen }\end{array}$ & $\begin{array}{l}\text { Número de } \\
\text { Trabajadores }\end{array}$ & $\begin{array}{l}\text { Intervalos (6) } \\
\text { - Menos de } 10 \\
\text { - } 10 \text { a } 49 \\
\text { - } 50-249 \\
\text { - } 250-499 \\
\text { - Más de } 499 \\
\text {-NS/NC }\end{array}$ & $\begin{array}{l}\text { Fayos, Calderón y Mir (2011); Lucanera y González } \\
\text { (2011); Buisán y Espinosa (2007); Calderón (2007); } \\
\text { Rodríguez y González (2006); Martín Armario, } \\
\text { (2003); Fernández y Nieto (2002); Katsikeas, } \\
\text { Leonidou y Morgan (2000); Christiansen et al. } \\
\text { (1987); Johanson y Valhne (1977); Johanson y } \\
\text { Wiedersheim-Paul (1975). }\end{array}$ \\
\hline Sector & $\begin{array}{l}\text { Tipo de Proceso } \\
\text { Productivo que se } \\
\text { ejecuta }\end{array}$ & $\begin{array}{c}\text { Sector } \\
\text { Económico }\end{array}$ & $\begin{array}{l}\text { Nominal(4) } \\
\text { - No clasificados } \\
\text { - Primario } \\
\text { - Secundario } \\
\text { - Terciario } \\
\end{array}$ & $\begin{array}{l}\text { López Mielgo (2007); Vila y Kuster (2007); } \\
\text { Rodríguez y González (2006); Oviatt y McDougall } \\
\text { (2005); Westhead, Binks, Ucbasaran y Wright } \\
\text { (2002); Shrader et al. (2000). }\end{array}$ \\
\hline $\begin{array}{l}\text { Resultados } \\
\text { de Innovación }\end{array}$ & Inversión en l+D & Innovación & $\begin{array}{l}\text { Variable Dicotómica } \\
\text { Valor Si/No }\end{array}$ & $\begin{array}{l}\text { Águila Obra y Meléndez (2010); Leal y Roldán } \\
\text { (2006); Camelo, Martín, Romero y Valle (2000); } \\
\text { DeCarolis y Deeds (1999); Bueno (1998); Samiee, } \\
\text { Walters y Dubois (1993); Morrison y Roth (1992); } \\
\text { Czinckota (1982); Cavusgil (1980); Bilkey y Tesar } \\
\text { (1977). }\end{array}$ \\
\hline $\begin{array}{l}\text { Resultados } \\
\text { Económicos }\end{array}$ & $\begin{array}{l}\text { Total de transferen- } \\
\text { cias de producto, } \\
\text { servicio, idea u otro } \\
\text { a un comprador } \\
\text { mediante el pago de } \\
\text { un precio convenido } \\
(€) \\
\end{array}$ & $\begin{array}{l}\text { Porcentaje de } \\
\text { Ventas en el } \\
\text { Exterior }(€)\end{array}$ & $\begin{array}{l}\text { Intervalos (6) } \\
\text { - Menos del } 5 \% \\
\text { - Entre } 5 \% \text { y } 15 \% \\
\text { - Entre } 15 \% \text { y } 25 \% \\
\text { - Entre } 25 \% \text { y } 50 \% \\
\text { - Más de } 50 \% \\
\text { - NS/NC } \\
\end{array}$ & $\begin{array}{l}\text { Tabares (2012); Weiss, López, y Medina (2011); } \\
\text { Rodríguez y González (2006); Fernández y Nieto, } \\
\text { (2002); Cortés y Ramón (2000); Katsikeas, } \\
\text { Leonidou y Morgan (1998); Shoham (1998); } \\
\text { Kirpalani y Balcome (1987). }\end{array}$ \\
\hline $\begin{array}{l}\text { Nivel de } \\
\text { Internaciona- } \\
\text { lización }\end{array}$ & $\begin{array}{l}\text { Mercados exteriores } \\
\text { dónde se vende pro- } \\
\text { ductos y/o servicios }\end{array}$ & $\begin{array}{c}\text { Presencia en los } \\
\text { mercados }\end{array}$ & $\begin{array}{l}\text { Nominal (5) } \\
\text { - UE } \\
\text { - África } \\
\text { - Latinoamérica } \\
\text { - Norteamérica } \\
\text { - Asia }\end{array}$ & $\begin{array}{l}\text { Hernández, Serna, y Carrillo (2011); Weiss, López, } \\
\text { y Medina (2011); Paunović y Prebežac (2010); } \\
\text { Esteve, Pallardó y Requena (2009); Fernández, } \\
\text { Peña y Hernández (2008); Kotler y Amstrong } \\
\text { (2008); Lamb y Hair (2006); Anderson y Gatignon } \\
\text { (1986). }\end{array}$ \\
\hline $\begin{array}{l}\text { Comercio } \\
\text { Electrónico }\end{array}$ & $\begin{array}{l}\text { Compra y venta de } \\
\text { productos o de ser- } \\
\text { vicios a través de } \\
\text { Internet }\end{array}$ & $\begin{array}{l}\text { Canal de } \\
\text { Distribución: } \\
\text { Internet }\end{array}$ & $\begin{array}{l}\text { Variable Dicotómica } \\
\text { Valor Si/No }\end{array}$ & $\begin{array}{l}\text { Chamorro y Miranda (2003); Meseguer, Rodríguez- } \\
\text { Ardura y Vilaseca (2003); Fader y Hardie (2000); } \\
\text { Matías et al. (2000); Doherty et al. (1999); Evans y } \\
\text { King (1999); Li et al. (1999); Swaminathan et al. } \\
\text { (1999). }\end{array}$ \\
\hline
\end{tabular}

FUENTE: Elaboración Propia. 


\subsection{Descripción de la población y muestra}

Nuestro análisis exigió iniciar la investigación delimitando un objeto material: las empresas (cooperativas y sociedades laborales) que integran el sistema Economía Social Andaluz. En este sentido, el Ministerio de Trabajo e Inmigración, cifró en 5543 el número total de sociedades activas (cooperativas y sociedades laborales) en 2002 en Andalucía (Clemente et al., 2008). Mientras que al cierre de 2013, este total ascendía a 7026 empresas de Economía Social (CEPES-Andalucía, 2013).

Las Empresas de Economía social andaluzas se distribuyen provincialmente de manera casi homogénea. Todas las provincias andaluzas poseen entre el 10 y 14 por ciento sobre el total de empresas de Economía Social regional, salvo Sevilla que concentra al 21\% (CEPES-Andalucía, 2013), es decir, existe un total de 1470 empresas de Economía Social hispalenses. Por su origen, aglutina un importante porcentaje de las exportaciones andaluzas, de esta manera Extenda (2014) anunciaba, en un "Encuentro sobre Internacionalización y Exportación de las Empresas de Economía Social" celebrado en Sevilla, que la mayor parte de las empresas andaluzas de Economía Social que utilizan sus servicios está radicada en la provincia, con un total de 120 empresas (26\%).

En la siguiente descripción técnica se incluyen los datos compilados de esta investigación, cuya recogida se ha realizado en 2003 y en 2014 comportando la misma metodología. Es importante señalar que se tratan de universos distintos, si bien al inicio de la investigación partíamos de una fuente primaria en relación a la base de datos de las empresas, transcurrido el tiempo gran parte de la muestra de 2002 no se localizó. Por otra parte, tenemos una limitación derivada de que las fuentes secundarias no revelan el total de empresas de Economía Social exportador de Sevilla en 2002, repercutiendo como desconocido en el estudio. Llegado 2013, si se tomó como población de referencia la propia de empresas exportadoras de la provincia. Resultando, los datos que se utilizan para realizar la investigación de carácter primario, además de, carácter específico, longitudinal y externo (inexistentes hasta el proceso de recogida de información propia del elemento muestral). Es necesario decir, pues, que la metodología del estudio se ha centrado en las empresas exportadoras localizables.

Finalmente, señalar que el proceso metodológico presenta una variación específica en el segundo momento del desarrollo derivado de la falta de recursos económicos como consecuencia de la crisis, así como, a la mortalidad empresarial propia de la misma, entre otras razones. 
Tabla 3. Ficha Técnica

\begin{tabular}{|l|l|l|}
\hline Metodología & \multicolumn{1}{|c|}{2002} & \multicolumn{1}{|c|}{2013} \\
\hline Proceso metodológico & $\begin{array}{l}\text { Encuestas telefónicas, y en su mayoría } \\
\text { mediante una entrevista personal de una } \\
\text { duración aproximada a 45 minutos. }\end{array}$ & $\begin{array}{l}\text { Encuestas telefónicas, y en su mayoría mediante } \\
\text { una entrevista propia de una duración } \\
\text { aproximada a 25 minutos. }\end{array}$ \\
\hline Tipo de preguntas & Dicotómicas, Nominales e Intervalos & Dicotómicas, Nominales e Intervalos \\
\hline Universo poblacional & $\begin{array}{l}515 \text { empresas andaluzas de economía } \\
\text { social }\end{array}$ & $\begin{array}{l}\text { 74 empresas andaluzas de economía social que } \\
\text { exportan regularmente }\end{array}$ \\
\hline Muestra obtenida & $\begin{array}{l}200 \text { empresas sevillanas de economía } \\
\text { social que exportan regularmente }\end{array}$ & $\begin{array}{l}\text { 48 empresas sevillanas de economía social que } \\
\text { exportan regularmente }\end{array}$ \\
\hline Forma de contacto & Correo electrónico y teléfono & Correo electrónico y teléfono \\
\hline Método de muestreo & $\begin{array}{l}\text { Muestreo aleatorio simple para proporcio- } \\
\text { nes con un nivel de confianza del 95\% y } \\
\text { con el supuesto de máxima indeterminación } \\
(\mathrm{p}=\mathrm{q}=0,5) .\end{array}$ & $\begin{array}{l}\text { Muestreo aleatorio simple para proporciones con } \\
\text { un nivel de confianza del 95\% y con el supuesto } \\
\text { de máxima indeterminación }(\mathrm{p}=\mathrm{q}=0,5) .\end{array}$ \\
\hline Error & $\pm 5 \%$ & $\pm 8 \%$ \\
\hline Fecha de encuestación & Enero a Junio de 2003 & Enero a Junio de 2014 \\
\hline
\end{tabular}

FUENTE: Elaboración Propia.

\subsection{Selección de los métodos estadísticos}

Para contrastar las hipótesis que se formulan en esta investigación se ha elegido el método estadístico a descriptivos e inferencias, fundamentado en: frecuencias y tablas de contingencia. Junto a contrastes de hipótesis en comparación de proporciones en base a la prueba $z$.

La recogida de datos se realiza a través de la aplicación de técnicas de investigación cualitativa (dinámica de grupos para elaboración de cuestionario) y cuantitativas (cuestionario estructurado de naturaleza personal) durante los años 2003 y 2014. Así como, el empleo del SPSS/PC (V22) posibilita la generación de la información necesaria.

La extracción de los elementos muestrales, de dos grupos (200/48 empresas), se realiza mediante un procedimiento de muestreo aleatorio simple, fundamentado en el azar y aplicado mediante el empleo de tablas de números aleatorios. Por último, debemos señalar que procedimos a eliminar del análisis las respuestas desconocidas de ambos grupos, ya que en el 2002 se registran de forma cuantiosa y dificulta la comparación global de los datos.

Una vez codificados y tabulados los datos, el análisis estadístico de dicha información permite a los autores generar conocimiento útil para que, al menos potencialmente, los gestores y órganos directivos de las cooperativas y sociedades laborales, especialmente las andaluzas, orienten sus políticas comerciales internacionales y para que el personal investigador interesado amplíe su conocimiento sobre el sector exportador de la Economía Social de nuestra región y su impacto económico. 


\section{4.- Resultados}

Este apartado expone los resultados de nuestra investigación, distinguiendo dos bloques importantes desde los resultados macro hacia los resultados micro. En primer lugar, se perfilan los resultados empíricos de las exportaciones y de las empresas exportadoras de Andalucía y Sevilla en los últimos cinco años demostrando una significativa progresión exportadora de la región y la provincia en línea ascendente. Proseguimos comprobando el rendimiento exportador positivo de la región bajo el comportamiento empírico de las empresas de Economía Social exportadoras de Sevilla.

Cabe decir que, los resultados de nuestra investigación se van a presentar en el mismo orden en que se han expuesto las hipótesis, y la enumeración está versada fundamentalmente en la creencia que las empresas de Economía Social exportadoras se internacionalizan progresivamente y en paralelo o sintonía con el crecimiento de la actividad exterior de Andalucía. Estas empresas observan la progresión de su rendimiento exportador directamente proporcional a su nivel de internacionalización, resultados económicos e innovación.

\subsection{El comercio mundial y la dinámica exportadora andaluza, sevillana y de la Economía Social}

El efecto arrastre que tienen las exportaciones en la producción prácticamente no se discute; pero si tomamos en consideración que las exportaciones mundiales han crecido de forma importante, por encima del $5 \%$ de media, en los últimos veinte años (Gutiérrez et al., 2014), y que este crecimiento ha sido superior al que experimentó el PIB en dicho periodo, nos damos cuenta del aumento de la especialización de las economías, de la productividad y de la importancia del sector exterior en la evolución del PIB de las mismas.

Según la OMC en su Informe anual sobre el Comercio Mundial (OMC, 2013), el mayor crecimiento de las exportaciones mundiales en el PIB se ha mantenido tambien durante los años de crisis, si exceptuamos el 2009. Ello nos ha mostrado el valor que el sector exportador tiene para las economías en crisis, sobre todo para salir de ella, pues permite aumentar los horizontes para la producción nacional, mas allá del mercado interior. Concretamente, el crecimiento económico se sustenta en una economía abierta, en la evolución de la demanda interna y externa, pues son los países con mayor ritmo de crecimiento de las exportaciones los que experimentan mayor dinamismo económico. Raymon (1996:84) ya señalaba hace años, que dicha evidencia ha orientado numerosos trabajos tratando de justificar la contribución de la actividad exportadora al crecimiento económico a largo plazo. La diferencia básica entre las dos líneas argumentales que hay, tal como él señala, radica en considerar la existencia de un nexo causal entre exportaciones y crecimiento, o bien, que tanto las exportaciones 
como el crecimiento son la consecuencia de una mayor eficiencia productiva, pues la mayor eficiencia productiva se traduce en la expansión del output, y por tanto, la expansión de las exportaciones está en función del aumento de la eficiencia y del output.

En realidad, para conseguir crecer con más rapidez que los competidores, las actividades productivas de un país o región y sus empresas deben captar a través de las exportaciones cuotas crecientes de los mercados exteriores, para de esta forma aumentar y consolidar ventajas competitivas (Myro, 1992:5). Tanto es así, que Andalucía es la región que más ha visto crecer en términos relativos sus exportaciones respecto a las españolas y frente a las grandes comunidades autónomas exportadoras, como Madrid, Cataluña, País Vasco y Valencia, que han pasado tan sólo del 9,05\% en 2009 al 11,16\% en 2012, años de crisis económica (Gutiérrez et al., 2012). Dicho comportamiento unido al crecimiento de la demanda externa a partir de 2010 ha tenido como efecto una contribución de la demanda externa al crecimiento dado el comportamiento negativo de la demanda interna. En general, destaca el incremento del volumen de exportaciones y la caída de la inversión en el exterior de las Comunidades Autónomas españolas (Gutiérrez et al., 2014).

Desde la década de los ochenta el sector exterior español ha experimentado una evolución clara. Según Montero (2013), ha sido un cambio estructural que nos consolida como una economía abierta a los mercados internacionales, tanto es así que, hoy el sector exterior desempeña un papel clave en la recuperación económica. A lo largo de las últimas décadas, el sector exterior ha desempeñado un importante papel contra cíclico, afectando tanto a las mercancías como a los servicios. Ejemplo de ello, es como el aumento de la tasa de apertura ha venido asociado tanto al incremento del peso relativo de las exportaciones como de las importaciones (la tasa de apertura de bienes, entendida como la suma de las exportaciones e importaciones de bienes en términos del PIB ha pasado del 28,4 por 100 en 1988 a situarse por encima del 45 por 100 en 2013, como estima Montero (2013) en su estudio sobre la evolución experimentada por el sector exterior español desde 1988 hasta la actualidad).

El sector exterior está desempeñando actualmente un papel clave en el inicio de la recuperación de la economía española, en momentos en que la demanda nacional deprimida presenta tasas de variación negativas trimestre tras trimestre. Al mismo tiempo asistimos a una importante reducción del déficit exterior, lo que está permitiendo tener esperanzas en la recuperación del Producto Interior Bruto (PIB). Según Moya (2013), esta reducción, originada fundamentalmente por la disminución en el déficit por cuenta corriente, ha sido ocasionada por la balanza comercial que se va equilibrando progresivamente, ya que, si bien sigue presentando déficit, éste es cada vez menor en la medida en que las exportaciones crecen de forma moderada y las importaciones están disminuyendo, entre otros factores.

Que el sector exterior impulse una lenta recuperación económica en España y Andalucía no implica que se le pueda trasladar toda la responsabilidad. Es decir, no debemos olvidar que su peso en el PIB es muy inferior al de la demanda nacional, por lo que su repercusión es limitada, pero no es obstáculo para afirmar, que es necesario diversificar los mercados, algo que ya viene ocurriendo en los últimos 
años. Políticas a las que se apuntan Álvarez, Vázquez y Figueroa (2013), cuando afirman, que hay que promover la diversificación de mercados en áreas geográficas con alto potencial de desarrollo (Asia, África, entre otras), así como, establecer las bases de un modelo productivo de bajo nivel de dependencia.

\section{llustración 2. Tasa de variación de las exportaciones totales 2009-2013}

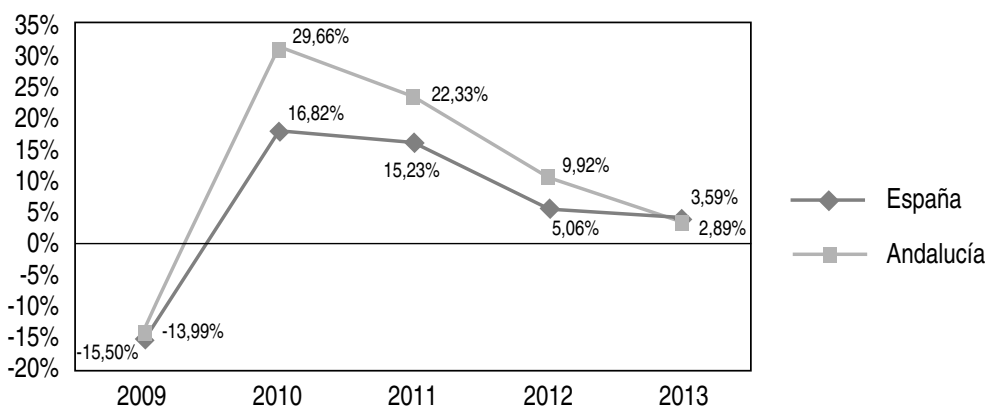

FUENTE: Elaboración propia a partir de datos de EXTENDA. ICEX, 2014.

En estos últimos años se ha expandido notablemente el número de empresas españolas que tiene intercambios con el exterior. La vigente crisis mundial ralentizó en sus inicios de forma acusada el ritmo de ampliación de la base exportadora, pero no lo interrumpió, lo que subraya la capacidad competitiva de las empresas exportadoras españolas facilitando la recuperación iniciada en 2010 y prolongándola hasta nuestros días (Belda y Gutiérrez, 2013:495).

Andalucía es una comunidad autónoma de peso en el comercio exterior español desde 1995. Aunque el saldo comercial de Andalucía es notablemente deficitario en la mayoría de estos años. A grandes rasgos se puede decir, que el análisis de la evolución del comercio exterior de las empresas andaluzas durante el periodo 2000-2009 se caracteriza por una descompensación de las exportaciones e importaciones, un saldo comercial negativo, una concentración sectorial y la congregación en su nivel de internacionalización en la Unión Europa (Ramón, Real y Castillo, 2010:48).

Las exportaciones totales regionales fueron de 25.969 millones de euros y en España alcanzaron 234.239 millones de euros en 2013. Si bien, entre 2008 y 2013 crecieron las exportaciones con independencia del año 2009, en el que al igual que sucede en Andalucía se registró una tasa de variación negativa. La comparativa nacional y regional es muy favorable a Andalucía, pues mientras que en España la tasa de variación del total de exportaciones fue del $23,79 \%$, en Andalucía ha sido del $54,28 \%$, lo que le ha permitido a Andalucía mejorar posiciones en el ranking exportador español de las comunidades autónomas. 


\section{llustración 3. Tasa de variación del número de empresas regulares 2009-2013}

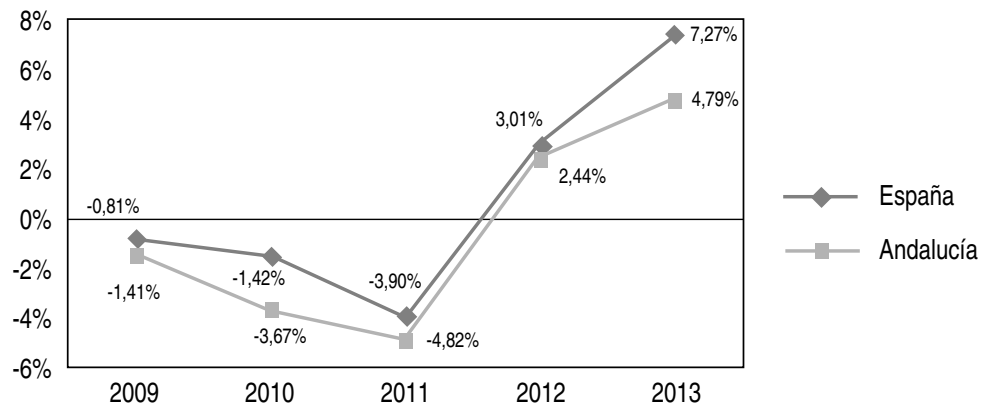

FUENTE: Elaboración propia a partir de datos de EXTENDA. ICEX, 2014.

Según los datos publicados por el Observatorio del Comercio Exterior de Andalucía de Extenda (2014), si nos fijamos solo en el número de empresas que exportan regularmente, mientras que en España la tasa de variación es positiva (3,84\%), en Andalucía fue negativa, con una caída del 2,97\% entre 2008 y 2013. Es decir, en Andalucía se ha producido un proceso de concentración de las exportaciones o crecimiento de las exportaciones por empresa del 49,35\%, que ha hecho aumentar las exportaciones regulares, de manera que han alcanzado un promedio por empresa de 5,42 millones de euros, un 3,44\% más que las españolas en 2013, cuando en 2008 exportaban un 15,8\% menos.

\section{llustración 4. Evolución número de empresas exportadoras}

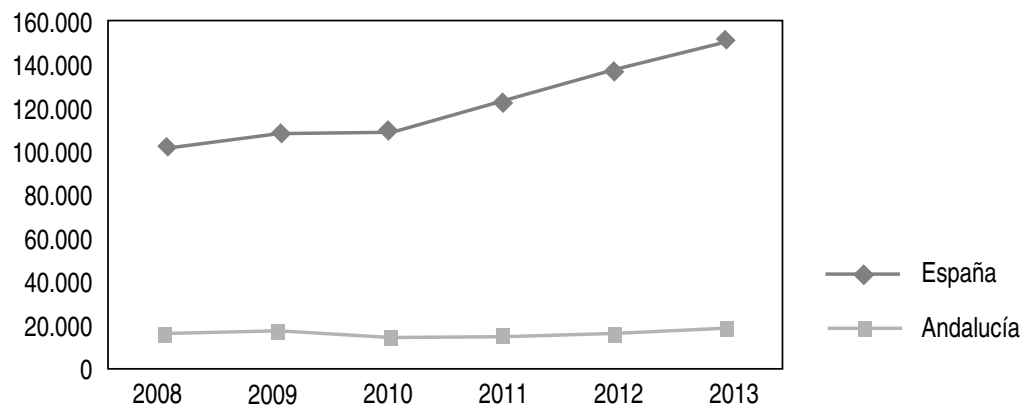

FUENTE: Elaboración propia a partir de datos de EXTENDA. ICEX, 2014.

Podemos observar que la evolución del número de empresas exportadoras en Andalucía ha evolucionado casi en paralelo a las nacionales en cuanto a los registros anuales de nuestra temporalidad marco. 


\section{llustración 5. Tasa de variación de exportación 2008-2013}

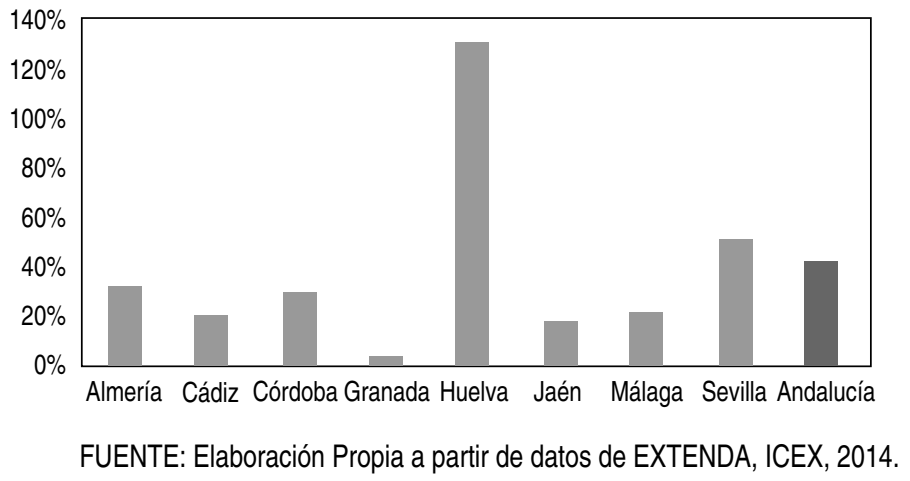

Dentro de la progresión exportadora de Andalucía, la dinámica exportadora de Sevilla es objeto de nuestro estudio. Se puede afirmar, que la evolución del número de empresas exportadoras en la provincia hispalense ha sido moderada a lo largo de estos últimos cinco años, manteniéndose de manera constante, así como, ocupando uno de los primeros puestos en el tejido empresarial consolidado y exportador de la región.

El comportamiento del sector exportador empresarial sevillano es bastante similar al regional, el número de empresas que exportan regularmente creció un $4,11 \%$, y la cantidad que exporta cada una de estas empresas lo hizo un 47\%, si bien esta cantidad media se situó en 4,72 millones de euros, un $12,9 \%$ y $9,93 \%$ menos que la media andaluza y española. Es decir la intensidad exportadora de las empresas sevillanas es menor que las andaluzas y las españolas.

\section{Ilustración 6. Evolución del número de empresas exportadoras de Sevilla}

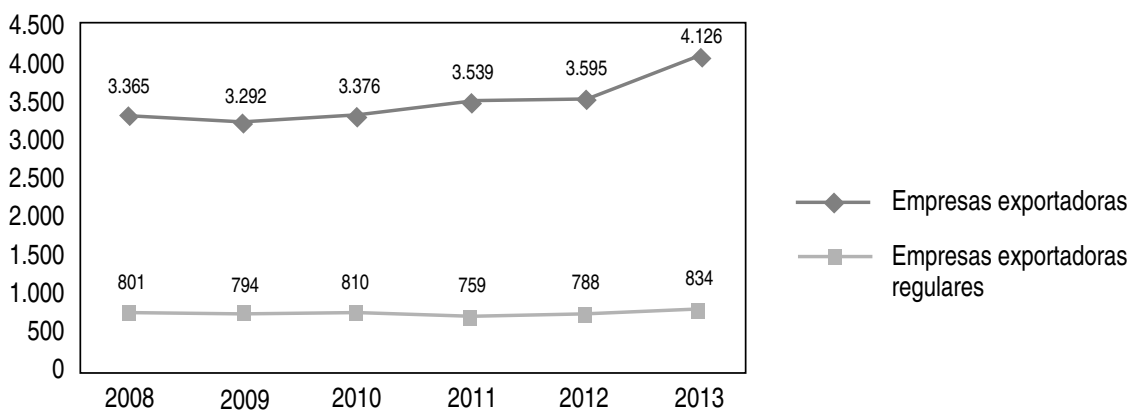

FUENTE: Elaboración propia a partir de datos de EXTENDA. ICEX, 2014. 
Podemos concretar el peso de las empresas exportadoras sevillanas mediante su evolución creciente, pues a pesar que en 2009 la tasa de variación fue negativa con respecto a $2008(-2,17 \%)$, a lo largo de los años restantes esta tasa de variación ha sido positiva, llegando a suponer un incremento de empresas exportadoras del 14,77\% en 2013.

Sin duda, la dinámica exportadora regional se traduce en la Economía Social de forma directa y progresiva, tal y como, muestran las empresas exportadoras de Economía Social de la provincia de Sevilla.

\subsection{La dinámica exportadora de la Economía Social: Sevilla}

Llegados a este punto exponemos los resultados de nuestro estudio longitudinal de las empresas exportadoras de Economía Social de Sevilla.

\subsubsection{El sector exportador y las empresas de la Economía Social}

Las empresas de Economía Social exportadoras de Sevilla en 2002, mayoritariamente, pertenecen al sector primario $(63,57 \%)$. Al analizar su comportamiento en el tiempo, se comprueba que se ha producido un descenso, alzándose a favor las empresas exportadoras de Economía Social sevillanas con actividad en el sector secundario y terciario. Es decir, el sector secundario y el de los servicios con el paso del tiempo han incrementado su actividad, llegando a ocupar en 2013 más del 80\% de la actividad económica de Economía Social.

\section{llustración 7. Sectores económicos de las empresas exportadoras de Economía Social de Sevilla}

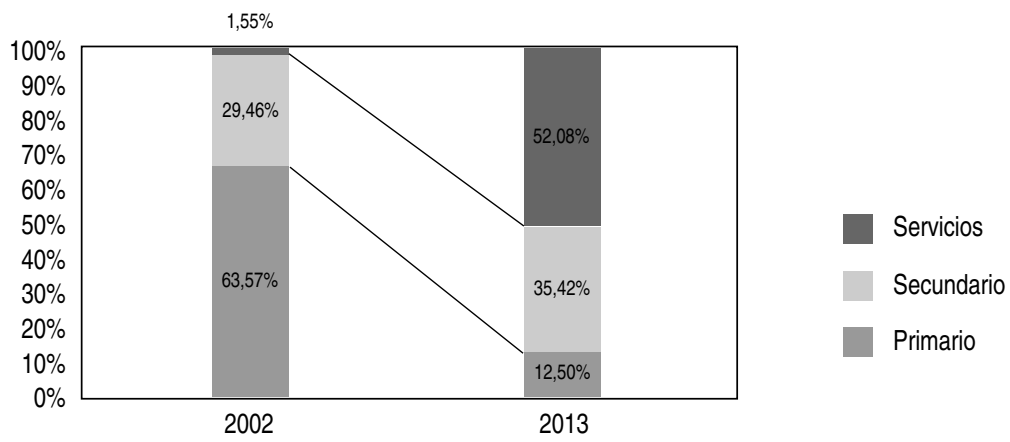

FUENTE: Elaboración propia. 
Se hace evidente, que el sector primario ha caído a favor del sector terciario, pues el aumento del sector secundario no es revelador, según ha demostrado la prueba z con nivel de significación 0,05.

\subsubsection{Tamaño empresarial y desempeño exportador}

En lo referente al tamaño empresarial, las empresas presentan un ascenso contundente en su número de trabajadores en el paso del tiempo, hecho que sucede especialmente en las empresas cuya plantilla es de 10 a 49 trabajadores, de 50 y 249 y las de más de 250 trabajadores. Un ascenso que en las empresas de 10 a 49 trabajadores se registra en una tasa de variación de 65,77\% entre 2002 y 2013.

\section{Ilustración 8. Tamaño de las empresas exportadoras de Economía Social de Sevilla}

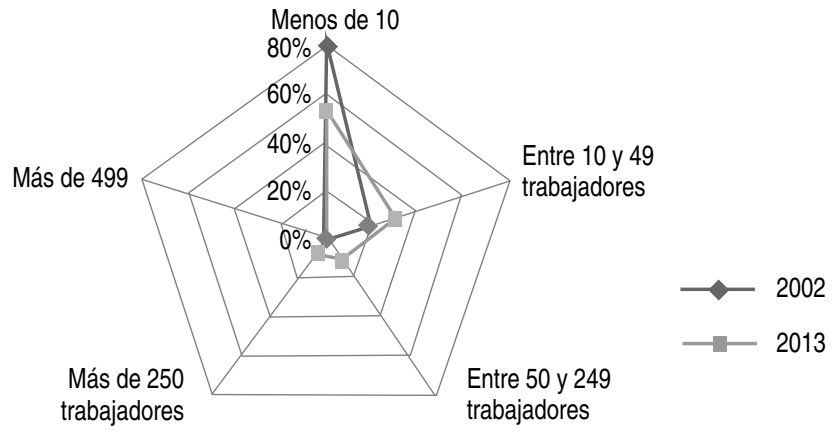

FUENTE: Elaboración propia.

Mediante un análisis descriptivo observamos que las empresas entre 10 y 49 trabajadores, de 50 a 249 trabajadores y con más de 250 trabajadores acentúan su peso entre las empresas exportadoras y sus exportaciones, mientras que, se reduce el peso de las empresas de menos de 10 trabajadores. Así, en 2002 las empresas de menos de 10 trabajadores representaban al 79,69\% del tejido empresarial exportador sevillano, y en 2013 se produce un descenso hasta el 53,19\%. Asimismo, las empresas cuyo tamaño estaba entre 50 y 249 trabajadores representaban el 1,56\% del tejido empresarial local exportador en 2002, y en 2013 era ya del $10,64 \%$.

Para reafirmarnos en lo dicho, hemos realizado la prueba $z$ a dichos porcentajes con un nivel de significación 0,05 , que no ha hecho más que ratificar lo afirmado en relación al tamaño de las empresas sobre los intervalos con menos de 10 trabajadores y entre 50-249 trabajadores. Habiendo comprobado de igual modo los resultados de las empresas entre 10 y 49 trabajadores y sin resultar trascendentes los mismos. 


\subsubsection{Innovación y desempeño exportador}

Las empresas de Economía Social exportadoras de Sevilla registran más resultados innovadores conforme a su experiencia en la actividad. Según nuestro estudio, en 2002 el $67,44 \%$ declaraba dedicar recursos a la innovación (I+D), mientras que en 2013 lo hacía el 95,24\% de las empresas.

\section{llustración 9. Inversión en innovación (I+D) de las empresas exportadoras de Economía Social de Sevilla}

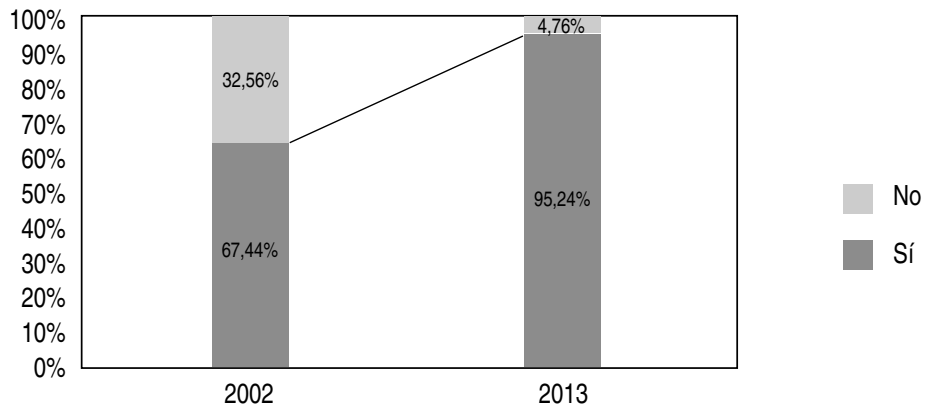

FUENTE: Elaboración propia.

\subsubsection{Crecen con el tiempo las empresas internacionalizadas, las ventas en el exterior y el uso de Internet}

Hemos podido comprobar, que el porcentaje de ventas en el exterior del total facturado por las empresas exportadoras de la Economía Social, presentan una variación especialmente positiva. Comparando los dos años 2002 y 2013, ha habido un incremento de las empresas que facturan menos de $5 \%$ en el exterior del total facturado, pero además, casi un 30\% de las empresas entrevistadas han revelado que su porcentaje de ventas en el exterior está entre el 5\% y el $15 \%$.

Está claro, que se ha producido una progresión de las ventas en el exterior respecto al total, pues cuando el 12,5\% de las empresas de la Economía Social sevillana que en 2013 facturaron más del $50 \%$ del total de ventas en el exterior, en 2002 solo alcanzaron el $5 \%$.

El aumento del número de empresas que facturan en los intervalos menos de $5 \%$ y entre $5 \%-15 \%$ es significativo. Así como, mediante la prueba $z$ con un nivel de significación 0,05 se ha evidenciado que los diferentes porcentajes de los otros grupos no presentan diferencias significativas. 


\section{Ilustración 10. Ventas en el exterior de las empresas exportadoras de Economía Social de Sevilla}

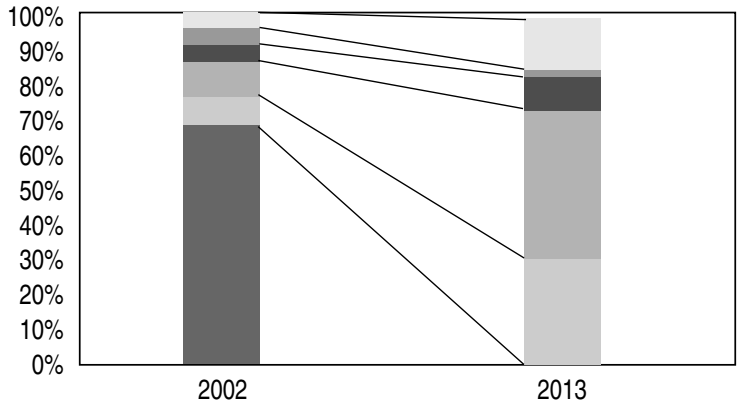

FUENTE: Elaboración propia.
Más $50 \%$

Entre el $25 \%$ y el $50 \%$

Entre el $15 \%$ y el $25 \%$

Entre el $5 \%$ y el $15 \%$

Menos del $5 \%$

Ninguno

A esto hay que sumar que el porcentaje de ventas en el exterior del volumen total facturado por estas empresas, presentan una variación significativamente positiva por el uso de internet como canal de distribución, de manera, que el comercio electrónico está en proceso de desarrollo.

A colación, en el estudio realizado por Gutiérrez et al. (2012:144-148) ya se detectaba como en 2010 las empresas andaluzas presentaban una situación favorable en distintos aspectos relacionados con las ventas. Según el mismo, un $26,7 \%$ de empresas andaluzas envían facturas electrónicas y un $20,2 \%$ recepcionan pedidos. Si comparamos sencillamente nuestros resultados con los citados del estudio que incluyen las ventas regionales y locales, parecen bastante coherentes, pues emerge un avance en el comercio electrónico. Es decir, si en 2002 no había empresas que vendieran al exterior por internet, en 2013 lo hacía el 10,42\%. De manera que hoy el comercio electrónico se ha convertido en algo más que un canal potencial de ventas.

\subsubsection{Relación entre en el nivel de internacionalización y el desempeño exportador}

La progresión al alza de la actividad exportadora de la Economía Social de Sevilla, también se ve reflejada en el aumento registrado de su nivel de internacionalización, entendiendo por esta, la presencia en más mercados. Es decir, hemos evidenciado, que las empresas de Economía Social han ido aumentando con el tiempo su presencia en los mercados exteriores. Mientras que en 2002, la exportación sevillana de Economía Social tímidamente operaba en la UE y África, en 2013 la actividad exportadora está afianzada en UE y Latinoamérica, seguida de África, Asia y Norteamérica respectivamente. 


\section{5.- Conclusiones, implicaciones, limitaciones y líneas futuras de investigación}

Las conclusiones empíricas primordiales que se derivan de esta investigación son las que se detallan a continuación.

$1^{a}$. Hemos comprobado, que las exportaciones andaluzas y las de la provincia de Sevilla han experimentado un importante crecimiento, que se ha visto afianzado por el crecimiento de las exportaciones por empresa en ambos territorios. Hecho que ha debido contribuir al crecimiento de ambas economías, o al menos, a que la recesión haya sido menor. En cualquier caso, defendemos que dicho comportamiento se ve reflejado en el sector de las empresas de Economía Social.

Las empresas exportadoras y sevillanas de Economía Social consideradas en esta investigación son pymes que presentan una actividad moderada de orientación exportadora a los mercados internacionales, y cuyo desempeño exportador está directamente vinculado a recursos internos como: tamaño, innovación, volumen de ventas, comercio electrónico y nivel de internacionalización.

Además, los resultados obtenidos también muestran que se sostienen todas las hipótesis planteadas, pues hemos comprobado, que el crecimiento exportador de los últimos años está protagonizado por un tejido empresarial con un desempeño exterior en progresión.

$2^{a}$. Se ha evidenciado, que el sector económico en el que están presentes las empresas exportadoras sevillanas de Economía Social viene influyendo en su desempeño exportador, pues los sectores con mayor dinamismo exterior de la Economía Social sevillana en 2013 eran el sector secundario $(35,42 \%)$ y el sector terciario $(52,08 \%)$, mientras que en 2002 el sector primario de la Economía Social exportaba el $63,5 \%$, de manera que se prueban los cambios que se derivan de la especialización sectorial.

En este sentido, apoyándonos en los trabajos de Canals y Carreró (1991) y Bartlett y Ghoshal (1991), cabe afirmar que el éxito de las operaciones internacionales lo determinan: la adaptación al sector, la eficiencia global, la sensibilidad nacional y desarrollo, y la transferencia de tecnología.

$3^{a}$. La tercera conclusión a la que llegamos refuta la tercera hipótesis. Hemos comprobado, que desde 2002 ha ido aumentando el peso de las empresas exportadoras sevillanas de Economía Social con mayor tamaño creciendo su desempeño exportador o su dinamismo. Se observa cómo entre 2002 y 2013 ha aumentado el porcentaje de empresas exportadoras con más de 10 y 50 trabajadores. 
Con el tiempo, el peso de las empresas de Economía Social de Sevilla con actividad exterior y con un número de trabajadores limitado $(<10)$ es menor o han sido menos dinámicas, una reducción significativa para un sector compuesto en su mayoría por pymes. Lo que nos confirma, que es necesario tener en cuenta la dimensión de las empresas exportadoras como requisito previo para la propia actividad exterior.

Puede ser que el tamaño de la empresa, si bien no es un factor totalmente determinante del proceso de internacionalización, sí parece condicionar sin embargo el proceso (Fayos, Calderón y Mir, 2011); así lo señala nuestra evidencia empírica, en que las empresas exportadoras de Economía Social con menos de 10 trabajadores es más dinámica en el tiempo y las empresas de entre 50 y 249 trabajadores ocupa más tejido empresarial con actividad exterior. Puede ser, porque no decirlo, que ello nos acerque a un ítem que incida en competitividad exportadora.

La refutación realizada está en sintonía con otros autores, afirmando, en general, que se encuentran diferencias significativas en productividad y tamaño entre las empresas que salen de la actividad exportadora y las supervivientes. Mientras que, Hollenstein (2005) señala que el tamaño de la empresa influye en la internacionalización solamente cuando la empresa es aún pequeña dado que este tipo de empresas se enfrentan a ciertas limitaciones físicas y financieras para lograr la internacionalización, indicador que se cumple en las empresas de Economía Social.

$4^{a}$ Comprobamos, que las innovaciones son determinantes en el mayor desempeño exportador de las empresas sevillanas de Economía Social. Es decir, las empresas de Economía Social exportadoras destinan más recursos a I+D, y como efecto exportan más. La constatación se observa como un proceso, pues en 2002 un 67,44\% de las empresas exportadoras invertían en l+D, y en 2013 el 95,24\%.

Según Bueno (1998) y para otros autores, el comportamiento exportador es una manifestación de la actitud innovadora de una empresa. Sin embargo, otros trabajos no llegan a las mismas conclusiones. Por ejemplo, Vila y Kuster (2007) recoge como las empresas más altamente internacionalizadas no son necesariamente las de más producto, ni las empresas de innovación de mercado.

$5^{\text {a }}$. Hemos comprobado el aumento que se ha producido del número de empresas exportadores de Economía Social que facturan en los intervalos menos de $5 \%$ y entre $5 \%-15 \%$, como significativos con el tiempo, pues, casi un $30 \%$ de las empresas que han respondido venden en el exterior dentro del último porcentaje señalado. Somos conscientes que hay distintos factores empresariales que condicionan la estrategia de expansión internacional y ejercen una notable influencia en el resultado exportador (ventas en el exterior) de la empresa (Bobillo et al., 2010).

También hemos detectado un aumento del uso de internet como canal de distribución, es decir, el comercio electrónico es un recurso más que potencial para las empresas. 
$6^{a}$. Por último, comprobamos que a medida que las empresas de Economía Social exportadoras operan en más mercados, mayores serán sus ventas en el exterior. La diversidad de países a los que exporta la empresa y la variedad de productos exportados influyen en la orientación internacional. Parece como hemos evidenciado, que la única forma de incrementar el compromiso exportador de las organizaciones es, aumentando el grado de internacionalización mediante la diversificación de los países a los que exporta, conclusión que comparten otros autores como Bueno (1998).

Lo que confirman las empresas exportadoras y sevillanas de Economía Social, es que progresivamente han ido adquiriendo presencia en mercados exteriores estando hoy afianzadas en UE y Latinoamérica, hecho que no sucedía en 2002, y exportando a África, Asia y Norteamérica.

Expuestos dichos resultados en forma de conclusiones, consideramos, que las hipótesis de nuestra investigación se sostienen, lo que nos permite concluir que las empresas exportadoras de Economía Social sevillanas estudiadas diseñan su estrategia competitiva internacional para tratar de mantenerla en base al desempeño exportador y un aumento de la competitividad que les permita aumentar el grado de internacionalización de forma creciente.

A continuación, hemos querido puntualizar las principales implicaciones teóricas y empíricas de esta investigación. La implicación principal de carácter teórico reside en que, basándonos en el conocimiento científico existente, se generan nuevas evidencias científicas que refutan la investigación previa sobre los tópicos desempeño exportador y crecimiento de economía abierta en un ámbito en el que la literatura presenta importantes deficiencias, como es el sistema de empresas de Economía Social regional y provincial (Sevilla).

En relación a las implicaciones empíricas de esta investigación sugerimos que sería adecuado para las empresas de Economía Social sevillanas incrementar su orientación internacional, de forma que aquellas empresas que no estén internacionalizadas se impliquen en un proceso de internacionalización, y aquellas que ya hayan iniciado este proceso avancen en las sucesivas etapas del proceso de internacionalización.

Una vez identificada la progresión exportadora de la provincia de Sevilla, consideramos que sería conveniente fomentar la creación de una red intraprovincial que permita especializar al mismo tiempo que difundir, el conocimiento ya generado por aquellas empresas internacionalizadas, así como, aprovechar las oportunidades creadas desde la sinergia.

La apuesta por un modelo de economía abierto a la competencia internacional permite a las empresas hacer frente a un mercado mucho más amplio $y$, por lo tanto, en primera instancia incrementar la facturación, reducir la variabilidad de las ventas al beneficiarse de una demanda potencial más amplia, organizar los recursos internos e incrementar su proceso innovador. 
En todo caso, el poder contar con más empresas exportadoras de Economía Social en Sevilla de forma regular es una condición necesaria para un mayor crecimiento de las exportaciones totales regionales. Solo creciendo la base de empresas exportadoras, los resultados podrán ayudar al tejido empresarial de Economía Social andaluz a optimizar sus estrategias de internacionalización, a forjar conocimientos específicos y a las entidades públicas a trabajar en consonancia en el impulso empresarial exterior.

Por otra parte, las limitaciones de esta investigación son de corte teórico y empírico. Ejemplo de ello, es la limitación primordial de corte teórico que guarda relación con la serie de variables trabajadas, pues se puede mejorar la precisión de las mismas en la definición de los indicadores, es el caso, de la definición de desempeño exportador, siendo además necesario aumentar el número de variables e indicadores considerados. Asimismo, se hace necesario diferenciar el dinamismo exportador en los diferentes tipos de cooperativas (agrarias, trabajo asociado, servicios, etc.).

En este trabajo se identifica el fenómeno de la internacionalización partiendo de la visión macroeconómica, pero avanzando en la visión empresarial desde el denominado modelo gradualista del proceso de internacionalización y la reciente literatura sobre desempeño exportador. Dicho esto, también cabe decir, que el enfoque gradual tiene sus detractores como así recogen Gankema, Snuif y Zwart (2000), pues se asume un camino prescrito para tener éxito. Los hallazgos de la investigación permiten validar el modelo en las pymes de Economía Social estudiadas evidenciando que la dinámica exportadora les permite crear un mayor compromiso de sus recursos en los mercados exteriores en la medida en que las empresas aumentan su capacidad de asumir riesgos (Tabares, Anzo, y Estrada, 2014).

Estando compuesta la Economía Social exportadora de Sevilla en su mayoría por pymes, y al igual que otros investigadores, hemos considerado que la concepción más integradora del proceso internacionalizador debería entrelazar la existencia de ciertas ventajas específicas de la empresa (de carácter productivo, tecnológico, organizativo, y/o comercial) con un relativo gradualismo. En definitiva, concebimos la internacionalización de la empresa de Economía Social como un proceso gradual de aprendizaje basado en la acumulación de una base de conocimientos a través de la experiencia, una experiencia decisiva a su vez en la puesta en marcha de este proceso.

Los resultados obtenidos deben ser entendidos en el marco descrito, es decir, nuestra muestra manejada se ha ceñido a Sevilla y se ubica en 2002 y 2013 para armonizar y homogeneizar resultados. La nueva y/o futura investigación podría hacerse para toda Andalucía, o quizás particularizar más la dinámica exportadora de la provincia de Sevilla como protagonista.

Tanto es así, que el grupo de investigación SEJ230: Planificación y Análisis Económico trabaja actualmente en perfeccionar los conocimientos de la realidad internacional en 2013 y 2014, plantear una investigación más consolidada, y tal vez, discriminante con la finalidad última de generar nuevo conocimiento que pueda ser potencialmente útil para orientar el cambio de modelo productivo de la economía local y regional y que pueda ser el origen de otras investigaciones. No debemos olvidar algo 
que ya señaló He y Wong (2004), hay pocas investigaciones empíricas que aborden el papel de varias variables en el desarrollo internacional de productos y procesos.

Moreno et al. (2008) ya indicaban que las futuras líneas de investigación, deben ir encaminadas a la realización de trabajos longitudinales, que permitan incorporar el carácter dinámico del proceso de internacionalización. De aceptarlo, nos llevaría directamente a observar los cambios incrementales del compromiso de las empresas con los mercados exteriores y su relación con la competitividad.

La investigación empírica presenta limitaciones imputables a los investigadores y, en este sentido, se considera que el carácter subjetivo de las variables seleccionadas, especialmente las relativas al desempeño exportador, podría considerarse como una limitación importante del trabajo, que pensamos subsanar, en la medida de lo posible, en futuras investigaciones.

\section{6.- Bibliografía}

ÁLVAREZ, J.A., VÁZQUEZ, P.C. \& FIGUEROA, C.S. (2013): "La economía española, su evolución y escenarios para la recuperación", CIRIEC-España, Revista de Economía Pública, Social y Cooperativa, 78, 203-243.

BARTLETT, C.A. \& GHOSHAL, S. (1991): "What is a global manager?", Harvard Business Review, 70(5), 124-132.

BELDA, J.I. \& GUTIÉRREZ, A.F. (2013): "Exportaciones españolas y su competitividad en el periodo 2006/2012". En: La Economía en la sociedad del (des) conocimiento, 1, 471-492. Delta.

BOBILLO, A.M., LÓPEZ-ITURRIAGA, F. \& TEJERINA-GAITE, F. (2010): "Firm performance and international diversification: The internal and external competitive advantages", International Business Review, 19(6), 607-618.

BORRELL, R.J. \& RELAÑO, R.G. (2009): "Binomio innovación-internacionalización y su relación con la estrategia en las empresas innovadoras localizadas en Andalucia", Scripta Nova. Revista Electrónica de Geografía y Ciencias Sociales, 13, 281-309.

BUENO, J.C.C. (1998): "El nivel de internacionalización de las empresas españolas con filiales en el exterior", Investigaciones europeas de dirección y economía de la empresa, 4(2), 91-108.

CALDERÓN, H., FAYOS, T. \& TURBILLEJAS, B. (2007): "El éxito en la internacionalización en un entorno global: planificación de marketing, cooperación y compromiso internacional", Mediterráneo económico, (11), 113-128. 
CANALS, J. \& CARRERÓ, R.T. (1991): Competitividad internacional y estrategia de la empresa, Ariel. CEPES-ANDALUCÍA (2013): Informe Estadístico de la Economía Social Andaluza, $4^{\circ}$ Cuatrimestre. Central de Estadísticas de la Economía Social de CEPES-Andalucía.

CHAMORRO, A.M. \& MIRANDA, F.J.G. (2003): "Factores determinantes de la adopción de Internet como canal de venta", Distribución y Consumo, 69, 100-104.

CLEMENTE LÓPEZ J., DÍAZ FONCEA, M. \& MARCUELLO SERVÓS, C. (2008): Estudio sobre las cooperativas y sociedades laborales en España: creación de empleo y contribución al desarrollo económico, Dirección general de la Economía Social, del trabajo autónomo y del Fondo Social Europeo, Ministerio de Trabajo e Inmigración, Código F08348, Universidad de Zaragoza.

COTEC (2010): Tecnología e Innovación en España, Informe COTEC 2010, Fundación COTEC para la Innovación Tecnológica, 1-317.

ESPASANDÍN BUSTELO, F. et al. (2003): Innovación y nuevas tecnologías en las empresas de Economía Social andaluzas, Ed. Consejería de Empleo y desarrollo tecnológico, Sevilla.

ESTEVE PÉREZ, S., PALLARDÓ LÓPEZ, V.J. \& REQUENA SILVENTE, F. (2009): "La dinámica de entrada y salida en mercados más competitivos. Su impacto en el periodo 1997-2005", Economía industrial, 373, 59-72.

FAECTA (2007): "Internacionalización de los Mercados. Diagnóstico de la situación de las Empresas Cooperativas Andaluzas de Trabajo Asociado". Investigación realizada por Federación Andaluza de Empresas Cooperativas, 1-85.

FAYOS T., CALDERÓN, H. \& MIR, J. (2011): "El éxito en la internacionalización de las cooperativas agroalimentarias españolas. Propuestas de un modelo de estudio desde la perspectiva del marketing internacional", CIRIEC-España, Revista de Economía Pública, Social y Cooperativa, 72, 43-72.

FERNÁNDEZ, Z. \& NIETO, M.J. (2002): La estrategia de internacionalización de la pequeña empresa familiar, Universidad Carlos III de Madrid, 1-26.

FUNDACIÓN UNICAJA (2014): Previsiones Económicas de Andalucía, 77.

GANKEMA, H.G., SNUIF, H.R. \& ZWART, P.S. (2000): "The internationalization process of small and medium-sized enterprises: an evaluation of stage theory", Journal of Small Business Management, 38(4), 15.

GARCÍA CANAL, E., GUILLÉN RODRÍGUEZ, M.F. \& VALDÉS LLANEZA, A. (2012): "La internacionalización de la empresa española. Perspectivas empíricas", Papeles de economía española.

GARCÍA, F.J.F., CAÑIZARES, S.M.S. \& ROLDÁN, L.M.S. (2011): "Cooperativas agroalimentarias y exportación. El proceso de internacionalización de la Cooperativa del Valle de Los Pedroches (COVAP)", REVESCO, Revista de Estudios Cooperativos, 104, 38-62. 
GARCÍA, H.C., GARDÓ, T.F., TAULET, A.C. \& ANDRÁS, B.T. (2007): "Selección del modo de entrada en un mercado internacional: valoración de las capacidades empresariales, la estrategia empresarial y la percepción de los problemas de la internacionalización", Información Comercial Española, ICE: Revista de economía, 839,143-162.

GONZALEZ, M.D.C.P. \& GARCÍA, M.J. (2012): "Dinámica territorial y economía social: una reflexión con especial referencia a Andalucía ante los cambios sociales", Revista de Estudios Empresariales, Segunda Época, 1, 40-58.

GUERRERO, D. (1995): Competitividad: Teoría y Política, Ed. Ariel, Barcelona.

GUTIÉRREZ FERNÁNDEZ, A. et al. (2012): La Competitividad e Internalización de la Economía Andaluza y de sus provincias y el nuevo modelo de crecimiento, Informe $n^{\circ} 1$, Patrocinado Fundación Cajasol y la Fundación de Investigación de la Universidad de Sevilla, Ed. Instituto de Estudios de Cajasol.

GUTIÉRREZ FERNÁNDEZ, A. et al. (2014): Informe sobre la internacionalización de la Economía Andaluza y de sus provincias y el nuevo modelo productivo, Informe $n^{\circ} 2$. Patrocinado Fundación Cajasol y la Fundación de Investigación de la Universidad de Sevilla, Ed. Instituto de Estudios de Cajasol.

HE, Z.L. \& WONG, P.K. (2004): "Exploration vs. exploitation: An empirical test of the ambidexterity hypothesis", Organization science, 15 (4), 481-494.

HERRERO, A.G. (2003): "La internacionalización de la economía española: la experiencia del sector bancario", Quórum: Revista de Pensamiento Iberoamericano, 5, 104-111.

HOLLENSTEIN, H. (2005): "Determinants of international activities: Are SMEs different?", Small Business Economics, 24 (5), 431-450.

JOHANSON, J. \& WIEDERSHEIM PAUL, F. (1975): "The internationalization of the firm-four Swedish cases 1", Journal of management studies, 12 (3), 305-323.

LOSADA PÉREZ, F., NAVARRO GARCÍA, A., RUZO SANMARTíN, E. \& BARREIRO FERNÁNDEZ, J.M. (2006): "La performance de exportación: revisión teórica y propuesta de un marco integrador", Investigaciones europeas de dirección de la empresa (IEDEE), 12 (1), 85-105.

MARTíN ARMARIO, J., ÁNGELES RASTROLLO HORRILLO, M. \& GONZALEZ ROBLES, E.M. (2009): "La internacionalización de la empresa: El conocimiento experimental como determinante del resultado en mercados exteriores", Cuadernos de Economía y Dirección de la Empresa, 12 (39), 123149.

MARTÍN-ARMARIO, J. (2003): Orientación al mercado y proceso de internacionalización de empresas, Universidad de Málaga.

MESEGUER, A., RODRÍGUEZ-ARDURA, I. \& VILASECA, J. (2003): "Situación y perspectivas del comercio electrónico en España: un análisis a través del volumen del negocio electrónico", Esic Market, 114, 77-107. 
MILLÁN VÁZQUEZ DE LA TORRE, M.G. \& NAVARRO, A.M. (2008): "El mercado de trabajo femenino en las empresas de Economía Social de Andalucía: un análisis econométrico del perfil de la mujer trabajadora", Pecvnia: Revista de la Facultad de Ciencias Económicas y Empresariales, Universidad de León, 7, 227-256.

MONTERO, A.F.M. (2013): "Diagnóstico de las necesidades y problemas a los que se enfrentan las empresas españolas: 1988-2013", Información Comercial Española, ICE: Revista de economía, 873, 11-22.

MORENO, F., PEÑA M.V., GARCÍA-PARDO, I. \& HERNÁNDEZ PERLINES, F. (2008): "Factores determinantes del éxito exportador. El papel de la estrategia exportadora en las cooperativas agrarias", CIRIEC-España, Revista de Economía Pública, Social y Cooperativa, 63, 39-64.

MORGAN, R.E. \& KATSIKEAS, C.S. (1998): "Exporting problems of industrial manufacturers", Industrial Marketing Management, 27 (2), 161-176.

MOYA, M.D.G. (2013): "El comportamiento del sector exterior español y su contribución a la recuperación económica", EXtoikos, 10, 25-30.

MYRO SÁNCHEZ, R. (1992): “Competitividad y especialización de la industria española”, FIES. Papeles de Economía Española, 81, 5.

NADAL, A. (2005): "La competitividad de la economía española", Información Comercial Española, ICE: Revista de economía, 826, 435-450.

ORGANIZACIÓN MUNDIAL DEL COMERCIO (OMC) (2013): Informe sobre el Comercio Mundial 2013: Factores que determinan el futuro del comercio, Publicaciones de la OMC.

OVIATT, B.M. \& MCDOUGALL, P.P. (2005): "Defining international entrepreneurship and modeling the speed of internationalization", Entrepreneurship theory and practice, 29 (5), 537-554.

PÉREZ, R.B. \& CARRILLO, B.E. (2000): Desarrollo local: Manual de Uso, ESIC Editorial, Madrid.

PÉREZ-SUÁREZ, M. \& ESPASANDÍN BUSTELO, F. (2014): "El proceso de internacionalización y los resultados de la innovación en las empresas de economía social andaluza", CIRIEC-España, Revista de Economía Pública, Social y Cooperativa, 82, 65-95.

PORTER, M.E. (1991): La ventaja competitiva de las naciones, Vol. 1025, Buenos Aires: Vergara.

RAMÓN, A.E., REAL, J.L.R. \& CASTILLO, D.J. (2010): "El comercio exterior andaluz durante el período 2000-2009. Análisis y perspectivas", Boletín económico de ICE, Información Comercial Española, 3001, 47-58.

SECRETARÍA GENERAL DE ECONOMÍA. Consejería de Economía, Innovación, Ciencia y Empleo. Junta de Andalucía (2014): Informe Económico Financiero, Presupuesto de la Comunidad Autónoma de Andalucía para el año 2015, 241- 279.

TABARES ARROYAVE, S.A. (2012): "Revisión analítica de los procesos de Internacionalización de las Pymes", Revista Científica Pensamiento y Gestión, 33, 67-92. 
TABARES, S., ANZO, E. \& ESTRADA, L.M. (2014): "La cooperación internacional en la internacionalización de pequeñas y medianas empresas de Medellín: un estudio de caso comparado", Estudios Gerenciales, 132, 314-324.

VILA, N. \& KUSTER, I. (2007): "The important of Innovation in international textiles Firms", European Journal of Marketing, 41(1/2), 17-36.

WEISS, V.V.G., LÓPEZ, M.S.E. \& MEDINA, L.H.B. (2011): "La distancia psíquica y el desempeño exportador: un reto para la Pyme en la era de la globalización", Estudios Gerenciales, 27(118), 85-96.

WELCH, L.S. \& LUOSTARINEN, R. (1988): Internationalization: evolution of a concept, Graduate School of Management, Monash University.

WERNERFELT, B. (1984): "A resource based view of the firm", Strategic management journal, 5(2), 171-180.

WONG, P.K. \& SINGH, A. (2004): "The pattern of innovation in the knowledge-intensive business services sector of Singapore", Singapore management review, 26(1), 21-44.

YUSTA, A.I., RUIZ, M.P.M. \& ZARCO, A.I.J. (2010): "Condicionantes económicos de la adopción de una innovación por parte del consumidor: análisis de la compra de servicios 'online', Innovar, Revista de Ciencias Administrativas y Sociales, 20 (36), 173-186.

ZOZAYA GONZÁLEZ, N. (2005): La innovación empresarial en España, Ed. Ministerio de Industria, Comercio y Turismo, 1-206. 